\title{
Unravelling the Mysteries of the Mesentery
}

\author{
Sunita Gopalan ${ }^{1}$ Vineetha Raghu ${ }^{1}$ \\ ${ }^{1}$ Department of Radiology, Columbia Asia Radiology Group, \\ Columbia Asia Referral Hospital, Bengaluru, Karnataka, India
}

\begin{abstract}
Address for correspondence Sunita Gopalan, MBBS, DMRD, FRCR, Department of Radiology, Columbia Asia Radiology Group, Columbia Asia Referral Hospital, Yeshwantpur, Bengaluru 560055, Karnataka, India (e-mail: gopalansunita@gmail.com).
\end{abstract}

\begin{abstract}
Keywords

- mesentery

- diseases

- masses

- nonneoplastic

The mesentery and its folds tether the small bowel loops to the posterior abdominal wall. It transmits nerves, vessels, and lymph ensconced in a fatty sponge layer wrapped in a thin glistening peritoneum, from and to the small bowel. Not only does this flexible dynamic fatty apron house various localized primary benign and malignant lesions, it is often involved in and gives an indication of generalized or systemic diseases in the body. An understanding of the anatomy, components, and function of the mesentery helps to classify mesenteric abnormalities. This further allows for characterizing radiological patterns and appearances specific to certain disease entities. Recent reviews of mesenteric anatomy have kindled new interest in its function and clinical applications, heralding the possibility of revision of its role in diseases of the abdomen.
\end{abstract}

\section{Introduction}

New concepts in mesenteric anatomy have brought it to the limelight in recent years as a possible new organ. ${ }^{1}$ Traditionally the mesentery is defined as a double layer of peritoneum that encloses an organ (bowel) and attaches it to the posterior abdominal wall. It is a supple lipomatous structure that allows and controls movement of the bowel. It transmits the vascular, lymphatic, and neural network that supplies the bowel. In its supporting role of the bowel, it gets intimately involved in the pathologies and diseases of bowel. However, it also retains its identity as an independent entity by virtue of its contents. This review aims to help gain an understanding of primary and secondary diseases of the mesentery both mass and nonmass abnormalities and the varied radiological patterns of presentation. It also attempts to categorize diseases of mesentery with a case-based approach to direct interpretation when presented with a mesenteric abnormality. It briefly touches upon historical and traditional concepts of the mesentery, as well as current and future concepts, to engage the reader's interest in the possibility of new developments in the role of the mesentery in disease management.

\section{Historical Outline}

The earliest description of the "mesenterium" as a continuous membrane subtending the bowel dates back to Aristotle. ${ }^{2}$ Thereafter in the 18th century, Toldt and Rosa revisited the anatomy of the mesentery and described a fascial plane found between the mesothelium of the mesocolon and the retroperitoneum that contained lymphatics. ${ }^{3-5}$ However, the current and traditional approach to mesenteric anatomy has been derived from the lectures published and expounded by a Royal British Surgeon to Queen Victoria, Sir Frederick Treves, ${ }^{4}$ and the 19 th century radiologist Wylie J. Dodds who propounded the presence of a primary retroperitoneum and a secondary/anterior retroperitoneum ${ }^{5}$ "bounded by folded fused leaves of mesentery that contained distinct pancreaticoduodenal and colonic subcompartments."

\section{Anatomy of the Mesentery}

The abdomen and its organs are lined by parietal and visceral peritoneum. The reflections of the peritoneum around the solid and hollow organs of the abdomen connect them to
DOI https://doi.org/ 10.1055/s-0040-1718247 ISSN 2581-9933.
(C2020. Indian Society of Gastrointestinal and Abdominal Radiology. This is an open access article published by Thieme under the terms of the Creative Commons Attribution-NonDerivative-NonCommercial-License, permitting copying and reproduction so long as the original work is given appropriate credit. Contents may not be used for commercial purposes, or adapted, remixed, transformed or built upon. (https://creativecommons.org/licenses/by-nc-nd/4.0/).

Thieme Medical and Scientific Publishers Pvt. Ltd. A-12, 2nd Floor, Sector 2, Noida-201301 UP, India 
one another and the posterior abdominal wall, holding them within the peritoneal cavity. The nerves to the small bowel from the splanchnic system have both sympathetic and parasympathetic components that course through the mesentery, but the definitive anatomy of these fibers in the mesentery is yet not clearly defined. ${ }^{6}$ Lymphatic vessels and nodes in the mesentery complete the mesenteric structure and contribute to its physiology and pathology.

Traditionally, a true mesentery is one that connects bowel to the posterior abdominal wall as follows:

- The small bowel mesentery proper containing the superior mesenteric artery (SMA), vein, and its branches.

- The transverse mesocolon containing the middle colic artery vein and its branches.

- The sigmoid mesocolon containing the sigmoid artery and vein and the superior rectal vessels.

The root of the small bowel mesentery is approximately 15-cm long, extending from the left of L2 vertebra at the duodenojejunal flexure to the ileocecal valve. ${ }^{7-9}$

It communicates with the transverse mesocolon at the formation of the gastrocolic trunk and with the hepatoduodenal ligament via the superior mesenteric vein (SMV) and portal vein. ${ }^{10}$ The transverse mesocolon divides the peritoneal cavity into supramesocolic and inframesocolic compartments, while the root of the small bowel mesentery divides the inframesocolic compartment into right and left infracolic spaces directing the flow of fluid within the abdomen ${ }^{11}$ (-Figs. 1 and 2).

\section{Imaging of the Mesentery}

\section{Conventional Radiography}

The mesentery being a predominantly fat-filled structure cannot be adequately imaged by conventional radiography. Calcifications and displacement of bowel loops due to masses may be seen on radiographs of abdomen and direct further imaging.

\section{Ultrasound}

Ultrasound (US) is the most accessible modality for the initial screening of the abdomen in both adults and children. Being freely available and radiation free, it is the investigation of choice in any patient presenting with an intra-abdominal mass.

\section{Barium Studies}

Mesenteric lesions, such as lymphoma, carcinoid, metastases, and tumors, may be seen as separation and or displacement of bowel loops in a barium meal follow-up through examination. ${ }^{12}$ However, there is currently no role for barium studies or enteroclysis in the evaluation of the mesentery.

\section{Computerized Tomography}

Multidetector computerized tomography (MDCT) with intravenous contrast-enhanced CT (CECT) with or without positive or negative oral contrast is possibly the frequently used and rational cross-sectional imaging modality for assessing and characterizing the mesentery and its diseases, with the added advantage of reconstruction in multiple planes. ${ }^{13}$ Volume and three-dimensional (3D) rendering enhance viewing aesthetics.

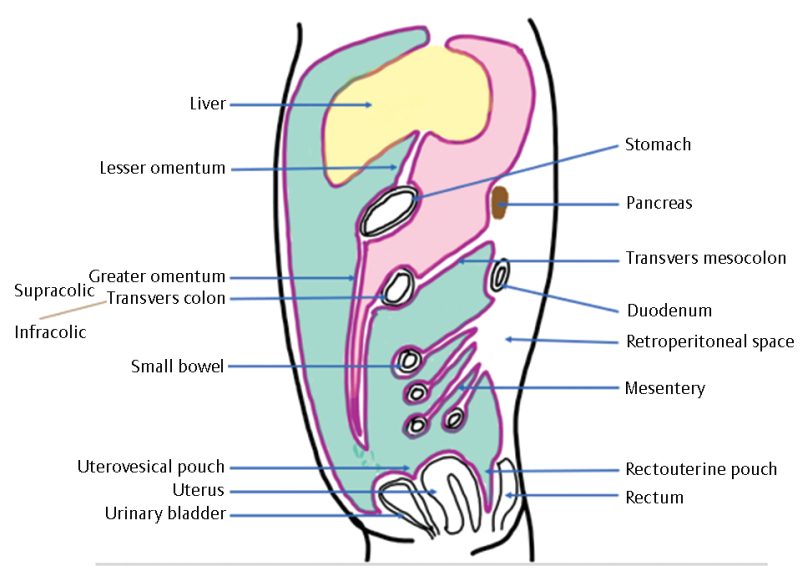

Fig. 1 Diagrammatic representation of the small bowel mesentery.
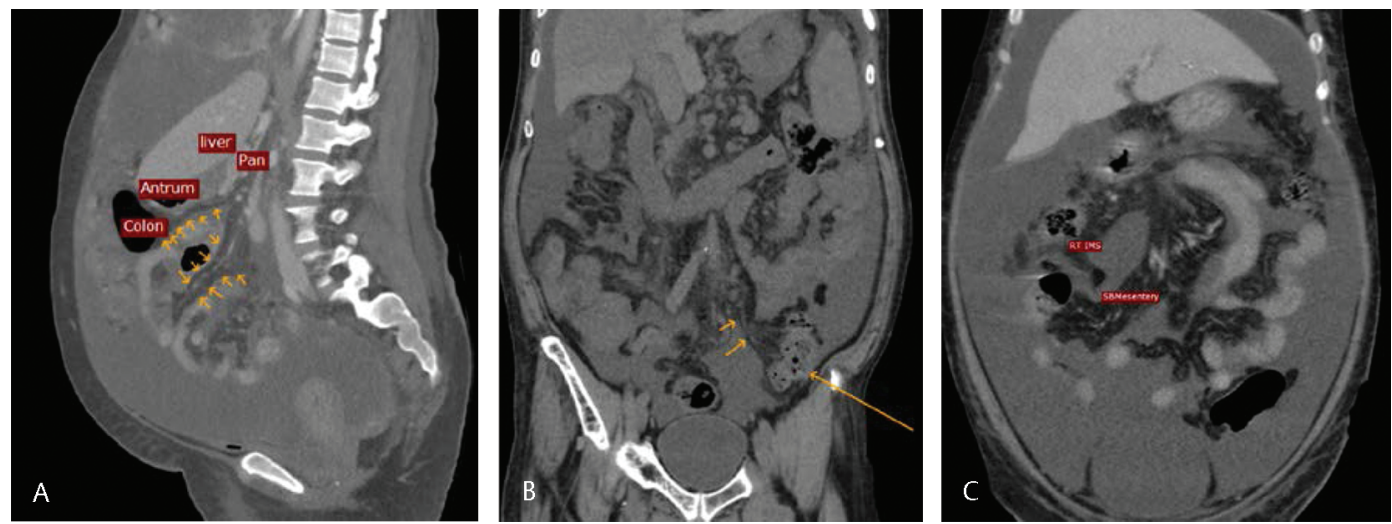

Fig. 2 Anatomy of the mesentery. (A) Reformatted sagittal CT section demonstrating transverse mesocolon and small bowel mesentery. (B) Reformatted coronal CT section demonstrating the sigmoid mesentery. (C) Reformatted coronal CT section demonstrating small bowel mesentery. CT, computed tomography; Pan: pancreas; RT IMS: right inframesocolic space; SB mesentery: small bowel mesentery. 


\section{Magnetic Resonance Imaging}

Although magnetic resonance imaging (MRI) lends itself to high soft-tissue resolution, MRI is used less commonly in routine practice for mesenteric abnormalities, being used more often as a problem-solving tool, especially in the characterization of tumors. Longer time of acquisition, as well as respiratory and bowel motion artifacts, may limit its usefulness depending on the case scenario. MR enterography is currently an important imaging tool used in assessment and follow-up of inflammatory bowel disease in both pediatric and adult patients.

\section{Mesenteric Diseases}

Mesenteric diseases have been categorized variously by various authors. In this review, mesenteric pathologies have been differentiated under two sections: mass like lesions and nonmass lesions of mesentery. Mass and mass-like lesions have been discussed and categorized simply as cystic, solid, and fatty lesions. Commonly and uncommonly encountered systemic, mechanical, and vascular entities involving the mesentery have been discussed under nonmass lesions of the mesentery for completion (- Fig. 3).

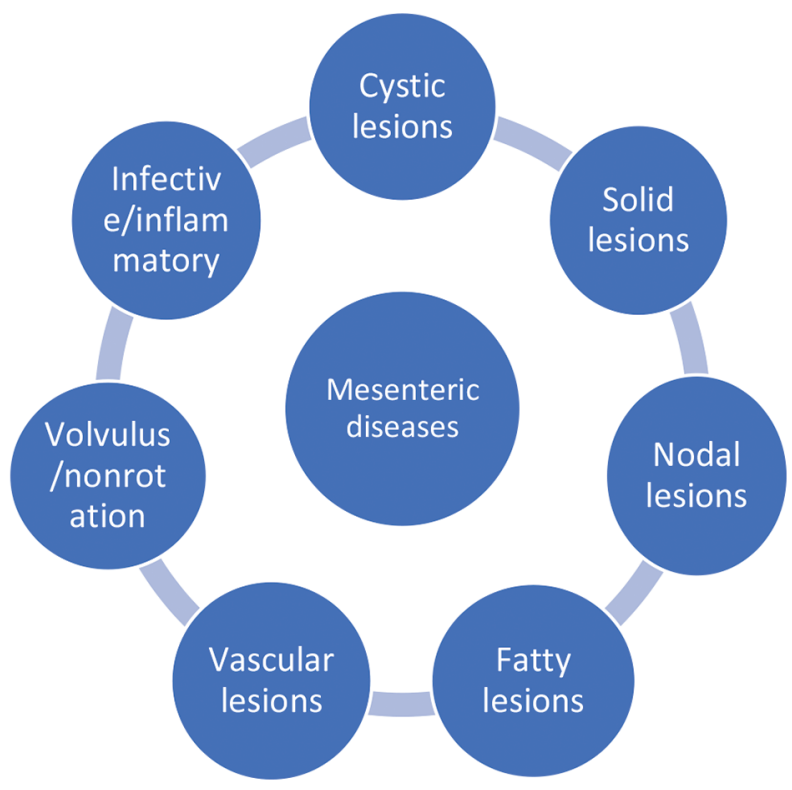

Fig. 3 Classification of mesenteric diseases.
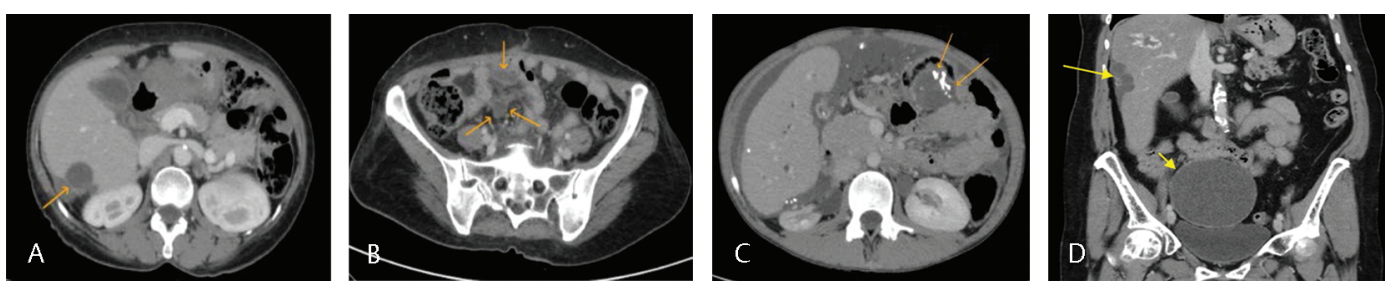

Fig. 4 Mucinous carcinomatosis: (A) A 51-year-old lady known carcinoma ovary, posthysterectomy presenting with hypodense mucinous metastatic deposits invading into the surface of right lobe of liver (arrows) and (B) deposits in the small bowel mesentery and serosa (arrows). (C) 21-year-old male with metastatic poorly differentiated mucinous adenocarcinoma of the rectosigmoid demonstrating mucinous deposits with punctate calcification (arrows). (D) Primary pseudomyxoma peritonei in a 74-year-old patient with past surgical history of mucinous appendiceal neoplasm on regular follow up, presenting with scalloping mucinous deposits on liver (long arrow) and recurrent mucin in the abdomen (short arrow). 
deposited on mesentery, serosal, and peritoneal surfaces. ${ }^{14}$ Calcification within the mucinous deposits are likely to be amorphous, scattered punctate, or punctate clusters ( - Fig. 4C). This condition is sometimes termed high-grade pseudomyxoma peritonei or peritoneal mucinous carcinomatosis, indicating direct invasion and infiltration of peritoneal surfaces by cellular components of the deposits. At surgery, these deposits are prone to rupture with spillage into the peritoneal cavity, hence having a poorer prognosis. ${ }^{13-15}$ Multidetector CT with reformatted sections allows for detection of 5- to $10-\mathrm{mm}$ hypodense nodules with or without soft-tissue attenuation which could represent solid tumor elements, compression of mesentery, or fibrosis..$^{13} \mathrm{MRI}$ allows for excellent depiction of bright hyperintense mucinous deposits on T2-weighted fat-suppressed and postcontrast T1-weighted images in hidden areas, having a greater sensitivity for smaller nodules but is often not the primary modality of choice due to cost constraints and longer time of study. ${ }^{14}$

\section{Mesenteric Abscess, Infections}

Intra-abdominal abscesses are commonly associated with diverticulitis, appendicitis, or surgeries. Postoperative mesenteric abscess ( $\mathbf{- F i g}$. 5A) and pancreatitis-related fat necrosis with mesenteric abscesses are diagnosed in the appropriate clinical setting. Mesenteric abscesses of all sizes are best seen at CECT as focal interloop/intra-abdominal irregular or well defined peripherally enhancing, thin- or thick-walled hypodense lesions with or without septations and with or without pockets of air within. ${ }^{15}$

Extraintestinal manifestations of severe Crohn's disease with mesenteric abscesses, interloop fistulae ( - Fig. 5B) and enhancing enlarged nodes are also best seen at CECT/CT enterography. Findings of mesenteric hyperemia, comb sign, mesenteric fat proliferation, and bowel changes add to diagnostic confidence of Crohn's disease. ${ }^{16}$

Manifestations of abdominal tuberculosis closely resemble primary and secondary mucinous/nonmucinous peritoneal carcinomatosis with conglomerate necrotic mesenteric nodal masses presenting as mesenteric abscesses and loculated fluid appearing as mesenteric cystic collections. Ancillary imaging features of tuberculosis, such as splenomegaly, calcified granulomata in the liver, spleen or nodes, and miliary microabscesses in the liver and spleen may help lead to diagnosis. ${ }^{13}$ These may be associated with diffuse peritoneal enhancement, adjacent solid and necrotic nodes, omental caking, and ascites with or without radiological features of ileocecal tuberculosis ( - Fig. 5C, D). ${ }^{17}$

\section{Congenital and Acquired Mesenteric Cysts}

Cystic mesenteric lesions can be congenital or acquired. Prenatal diagnosis of intra-abdominal simple cysts raises the possibility of multiple differentials. Postnatal US assessment allows further characterization with respect to location (relationship to bowel or ovary), cyst wall morphology (gut signature in duplication cyst), internal debris (mesenteric, ovarian, and duplication cyst) (-Fig. 6A-C), fat content or calcification (dermoid), and wall calcification (meconium pseudocyst)..$^{18,19}$

A mesothelial cyst is uncommon and demonstrates a single layered wall with no internal content or septations. Anatomically, an enteric duplication cyst occurs commonly along the mesenteric border of the ileum, and is characterized by a multilayered wall at US demonstrating the "bowel signature." ${ }^{19}$ However, differentiation of duplication cyst from mesenteric and ovarian cysts on US remains challenging, especially when they are large. In a female neonate, an abdominopelvic cyst with debris needs to be considered ovarian in origin if one ovary cannot be separately visualized. There may be a "daughter cyst" within an ovarian cyst which represents a smaller cyst within a larger cyst. ${ }^{20}$

Calcification in the wall of a unilocular cyst in a neonate should raise the possibility of a meconium pseudocyst ( $\mathbf{- F i g . ~ 6 D , ~ E ) . ~ T h e y ~ c o m m o n l y ~ h a v e ~ a n ~ i r r e g u l a r ~ s h a p e ~ a n d ~}$ insinuate into peritoneal contours. ${ }^{20}$

A multiloculated intra-abdominal "infiltrative" cystic lesion is more commonly a lymphangioma. Lymphangioma may appear like an ascites in neonates on US. Absence of free fluid in the Morrison's pouch, paracolic gutters, and pelvic recesses allows differentiation from ascites. Further imaging with MRI/CT is indicated only as a problem-solving tool. These lesions demonstrate variable appearances on CT and MR depending on the presence of proteinaceous content, hemorrhage, or fat. ${ }^{21}$ These lesions may be closely adherent to the bowel, necessitating bowel resection. ${ }^{19}$

In adults, the differentials of mesenteric cystic lesions include congenital and acquired cysts (- Table 2 ). In addition to the cysts described above, the possibilities of pancreatic pseudocyst (-Fig. 7A), nonpancreatic pseudocyst, and hydatid cyst need to be considered. ${ }^{18,22}$

Nonpancreatic pseudocysts ( $\mathbf{- F i g}$. 7B, C) appear as thick walled septate lesions which may contain hemorrhage or
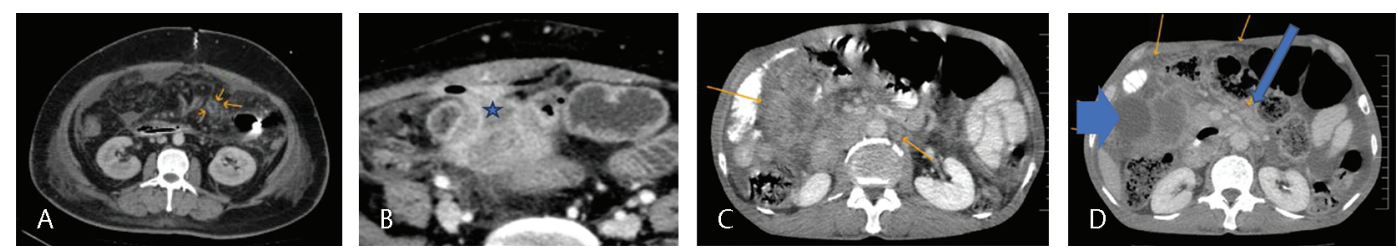

Fig. 5 Mesenteric abscess. (A) 51-year-old patient presenting with post-operative fever with a small mesenteric collection/ abscess (small orange arrows). (B) Interloop mesenteric abscess with irregular margins (blue star) in a patient with complicated Crohn's. (C, D) A known case of abdominal tuberculosis with cystic necrotic nodes at root of mesentery (blue arrows), ascites, and cystic loculated collections with peripheral enhancement (thick blue arrow) in addition to omental cake (yellow arrows). 

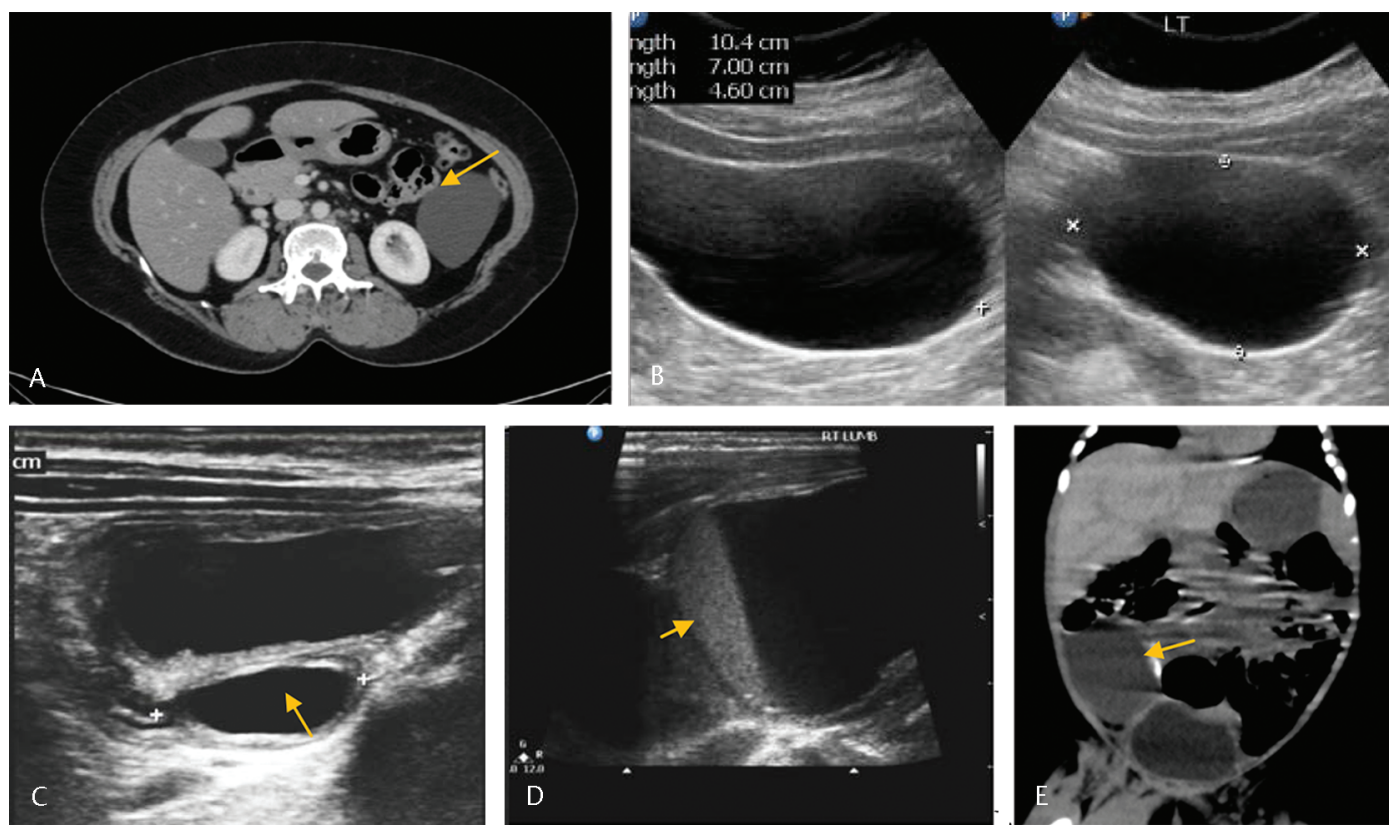

Fig. 6 Pediatric cystic mesenteric lesions (A, B) A young male with incidental thin walled non enhancing cystic lesion adjacent to the proximal jejunum (arrow) (B) Correlative US in the same patient, for characterization of wall and internal content demonstrates a simple cyst, most likely a mesothelial cyst. (C) A 6-year-old patient with incidental cystic lesion in the right iliac fossa. US demonstrates a multi-layered unilocular cystic lesion suggestive of a duplication cyst (arrow). (D, E) A neonate with suspected abdominal mass. US abdomen demonstrates an abdominal cyst with layered internal debris (arrow). Plain CT demonstrates eccentric wall calcification (arrow), proven meconium cyst at surgery. CT, computed tomography; US, ultrasonography.

Table 2 Classification of mesenteric cysts

\begin{tabular}{|c|c|c|c|c|}
\hline & Type & Wall & Loculation & Enhancement \\
\hline \multirow[t]{3}{*}{ Simple cystic } & Enteric duplication cyst & All layers of the gut & Unilocular \pm debris & $\begin{array}{l}\text { Multilayered non } \\
\text { enhancing/mildly enhanc- } \\
\text { ing wall }\end{array}$ \\
\hline & Enteric cyst & Enteric epithelium & Unilocular & Thin non enhancing wall \\
\hline & Mesothelial cyst & Mesothelium & Unilocular & Thin non enhancing wall \\
\hline \multirow[t]{6}{*}{$\begin{array}{l}\text { Mildly complex } \\
\text { cystic lesion }\end{array}$} & Lymphangioma & Lymphatic/endothelial lining & $\begin{array}{l}\text { Multilocular-chylous, } \\
\text { serous/hemorrhagic }\end{array}$ & $\begin{array}{l}\text { Wall and septae may or } \\
\text { may not enhance }\end{array}$ \\
\hline & $\begin{array}{l}\text { Pseudomyxoma } \\
\text { peritonei/mucinous } \\
\text { deposits }\end{array}$ & Avascular mucinous deposits & $\begin{array}{l}\text { Multilocular } \pm \text { internal } \\
\text { echoes }\end{array}$ & No enhancement \\
\hline & $\begin{array}{l}\text { Nonpancreatic } \\
\text { pseudocyst }\end{array}$ & $\begin{array}{l}\text { Fibrotic thick wall } \pm \text { wall } \\
\text { calcification }\end{array}$ & Unilocular & Thick wall \pm enhancement \\
\hline & Pancreatic pseudocyst & Fibrotic thick wall & Unilocular & Uniform wall enhancement \\
\hline & $\begin{array}{l}\text { Infectious tuberculosis/ } \\
\text { Crohn's disease }\end{array}$ & $\begin{array}{l}\text { Loculated ascites, necrotic } \\
\text { nodal mass } \\
\text { Abscesses }\end{array}$ & Multiunilocular & Rim enhancement \\
\hline & Infectious hydatid & $\begin{array}{l}\text { Outer pericyst, middle lam- } \\
\text { inated membrane and inner } \\
\text { germinal layer }{ }^{26}\end{array}$ & $\begin{array}{l}\text { Multiloculated } \pm \text { rim } \\
\text { calcification or total } \\
\text { calcification }^{27}\end{array}$ & Enhancing wall if infected \\
\hline $\begin{array}{l}\text { Cystic with solid } \\
\text { components }\end{array}$ & $\begin{array}{l}\text { Cystic mesenchymal } \\
\text { tumors, GIST }\end{array}$ & Necrotic tumor mass & $\begin{array}{l}\text { Unilocular with rim } \pm \text { solid } \\
\text { component }\end{array}$ & $\begin{array}{l}\text { Heterogeneously } \\
\text { enhancing }\end{array}$ \\
\hline
\end{tabular}

Abbreviation: GIST, gastrointestinal stromal tumor.

pus. They are remnants of prior mesenteric abscess or hematoma, often detected incidentally and may be mistaken for a hydatid cyst. ${ }^{19}$

Intra-abdominal hydatid cysts ( - Fig. 7D) may be single or multiple. While CT demonstrates extent of intra-abdominal dissemination of hydatids, US plays a key role in diagnosis of hydatid cysts with characteristic findings of daughter cysts, spoke wheel pattern, water lily sign (complete detachment of endocyst from pericyst), and floating membrane sign (partial separation of endocyst from pericyst). ${ }^{23} \mathrm{MRI}$ is used for 

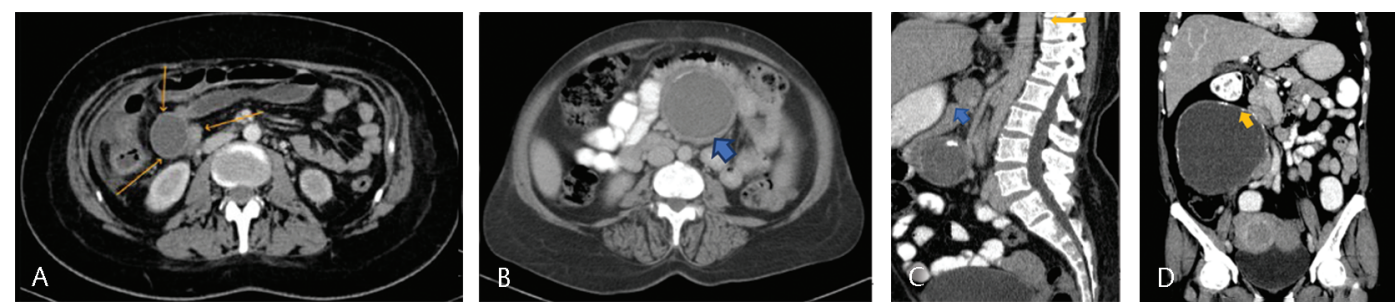

Fig. 7 Adult mesenteric cysts. (A) A young male with prior history of pancreatitis on follow up. CT demonstrates a pancreatic pseudocyst (arrows). (B, C) Incidentally detected well defined thick-walled mesenteric root cyst with wall calcification (blue arrow). Patient had no prior pancreatitis but gives history of prior trauma which is corroborated by old fracture D12 (yellow arrow) seen on sagittal reconstruction. In this context, a diagnosis of nonpancreatic pseudocyst was suggested and followed up. (D) Adult presented with suspected abdominal mass. CT demonstrated a well-defined lesion with rim calcifications and subtle internal vesicular cysts, hydatid cyst. CT, computed tomography.

reviewing complications of hydatids such as infection, cyst rupture, and intra-abdominal dissemination, in which case it may appear as a multiloculated mass (known as encysted peritoneal hydatidosis)..$^{23,24}$

Classification of cystic lesions as simple cystic (mesothelial and duplication cysts), mildly complex (lymphangioma, pseudomyxoma peritonei, pseudocyst, hydatid, and abscess), and cysts demonstrating solid components (malignancies) may help characterize mesenteric cystic lesions in adults on imaging. ${ }^{22}$

\section{Solid Lesions of Mesentery (Nonnodal)}

Solid nonnodal masses of the mesentery encompass several entities, the most common being metastases..$^{25,26}$ - Table 3 lists nonnodal solid mesenteric masses.

\section{Metastases}

Mesenteric invasion by metastases may be by blood, lymph, peritoneal seeding, and direct spread. Breast cancer, lung cancer, and melanoma spread to the mesentery by hematogeneous and lymphatic routes. Ovarian, pancreatic, breast, and colonic cancers spread commonly by peritoneal seeding, while direct extension into the mesentery occurs from pancreas and stomach. ${ }^{25}$

Calcified mesenteric deposits from ovary and mucinous tumors of the colon and stomach are usually associated with similar deposits in the peritoneum and omentum, and may thus be differentiated from calcified retractile mesenteritis and mesenteric carcinoid. ${ }^{26}$

Metastatic and lymphomatous nodal masses of the mesentery are rather common and will be discussed under nodal masses.

Sclerosing mesenteritis is a relatively uncommon inflammatory lesion of the mesentery ( - Fig. $\mathbf{8 A}$, B) seen predominantly in men in the sixth and seventh decades. ${ }^{26,27}$ Causation is yet undefined, but a strong association with prior abdominal surgery and immunoglobulin (Ig)-G4 related disease is documented. Sclerosing mesenteritis as a harbinger of lymphoma, urogenital, and gastrointestinal malignancies is yet unproven. ${ }^{26}$

- There are three histologic subtypes of sclerosing mesenteritis, or rather stages, namely, (1) mesenteric lipodystrophy (representing the first stage of fat necrosis and more of a pathological diagnosis), (2) mesenteric panniculitis,
Table 3 Solid nonnodal mesenteric masses

\begin{tabular}{|l|l|l|}
\hline Common & Uncommon & Rare \\
\hline - Peritoneal & - Carcinoid & - Inflammatory \\
metastases & - Primary peritoneal & pseudotumor \\
& carcinoma & - Soft tissue \\
& - Desmoid tumor & sarcoma \\
& - Sclerosing & - Desmoplastic \\
& mesenteritis & round cell tumor \\
& - Gastrointestinal & - Mesothelioma \\
& stromal tumor & \\
\hline
\end{tabular}
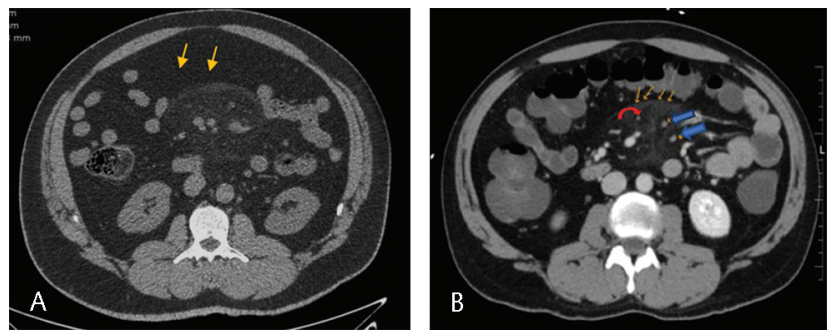

Fig. 8 Sclerosing mesenteritis (A) showing tumoral pseudocapsule (yellow arrows) (B) fat ring sign (curved red arrow) and nodules (blue arrows).

and (3) retractile mesenteritis. ${ }^{28}$ Imaging with CECT for abdominal pain and discomfort with or without fever demonstrates a mass-like soft-tissue attenuation infiltrating fat in the root of mesentery, referred to as mesenteric panniculitis in radiology parlance. The extent of inflammatory activity is defined by a thin line of soft tissue of less than 3-mm thickness, the tumoral pseudocapsule

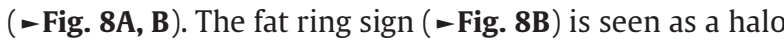
of fat sparing around mesenteric vessels within. ${ }^{29}$ In addition, the inflammatory mass may contain multiple soft tissue nodules, usually less than or equal to $5 \mathrm{~mm}$. Any nodule greater than $10 \mathrm{~mm}$ is concerning for malignancy and should be biopsied. ${ }^{25,30}$ These signs are key in differentiation of mesenteric panniculitis from "misty mesentery" in mesenteric edema or hemorrhage. ${ }^{31}$

Retractile mesenteritis occurs when inflammation progresses to fibrosis and a desmoplastic reaction results in a spiculated lobulated soft-tissue mass with or without internal cavitation or calcification. This causes shortening of the 
mesentery, kinking, and fixation of small bowel leading to small bowel obstruction. ${ }^{26,29}$

MRI in sclerosing mesenteritis demonstrates mildly hyperintense T1-enhancing soft-tissue mass, heterogeneously hyperintense, or diffusely hypointense on $\mathrm{T} 2$ depending on the amount of fibrosis. ${ }^{25}$ They do not demonstrate fluorodeoxyglucose (FDG) positron emission tomography (PET) avidity and thereby can be differentiated from lymphoma and other malignancies. ${ }^{32}$

Carcinoid tumor forms a very close differential for sclerosing mesenteritis. Primary mesenteric carcinoid is very rare. ${ }^{25,33}$ The mesentery is involved as a result of direct extension or lymphatic spread from a bowel primary, forming a hyper enhancing spiculated soft-tissue mass ( - Fig. 9A-C) with a stellate pattern as a result of proliferative desmoplastic reaction to the neuroendocrine substances released. ${ }^{26}$ The distal ileum, rectum, appendix, colon, and stomach are the most common sites of origin. ${ }^{34}$ Calcification is seen within this metastatic mass in approximately $70 \%$ of cases. ${ }^{35}$ Encasement of vessels and mesenteric infiltration may result in small bowel obstruction and ischemia. ${ }^{36}$

The fat ring sign is absent in metastatic mesenteric carcinoid. Often the primary carcinoid tumor in the bowel is undetectable, often being less than $2 \mathrm{~cm}$ in size. On CECT, the primary tumor enhances vividly with contrast. Octreotide scan is the most sensitive imaging modality for the diagnosis of neuroendocrine tumors and its metastases to lung, liver, peritoneum, and nodes. ${ }^{26}$ They are often associated with multiple endocrine neoplasia, neurofibromatosis type 1 , and other coexisting abdominal adenocarcinomas ${ }^{37,38}$ ( Fig. 9A).
Desmoid tumors are made of proliferating fibroblasts with intracellular collagen, sporadically seen in women in the third and fourth decades but also seen in patients with prior abdominal surgery or trauma. Other associations include Gardner's syndrome and familial adenomatous polyposis syndrome (FAPS). ${ }^{39}$

The site of origin of desmoid may be from abdominal wall, extra-abdominal or intra-abdominal. Within the abdomen, the mesentery is the preferred site of origin of these slow growing desmoids, with a majority of these lesions arising from near the SMA origin. ${ }^{40}$ Though they do not metastasize, they are known to be locally aggressive, infiltrating adjacent bowel, and vessels with stubborn recurrences. ${ }^{39}$

The propensity for recurrence and the tendency to aggression are, however, unpredictable. On CT and MRI, imaging and enhancement characteristics ( - Fig. 9D) are subject to the proportions of fibrous and cellular components. They can therefore be T2 hyperintense (myxoid components) to T2 hypointense (dense collagenous stroma) with mild-to-moderate enhancement patterns reflecting similar heterogeneity. Preoperative MRI can be particularly helpful in delineating soft-tissue character and planes. Notably fluid signal intensity with heterogeneous T2 hyperintensity and vivid postcontrast enhancement seen in postoperative follow-up MRI are indicators of growth as opposed to T2 hypointense residual bland fibrous residue. .0,41 $^{4}$

Inflammatory myofibroblastic tumors are uncommon tumors of mesenchymal origin seen in young adult girls and children, largely in lung, mesentery, and omentum. Though
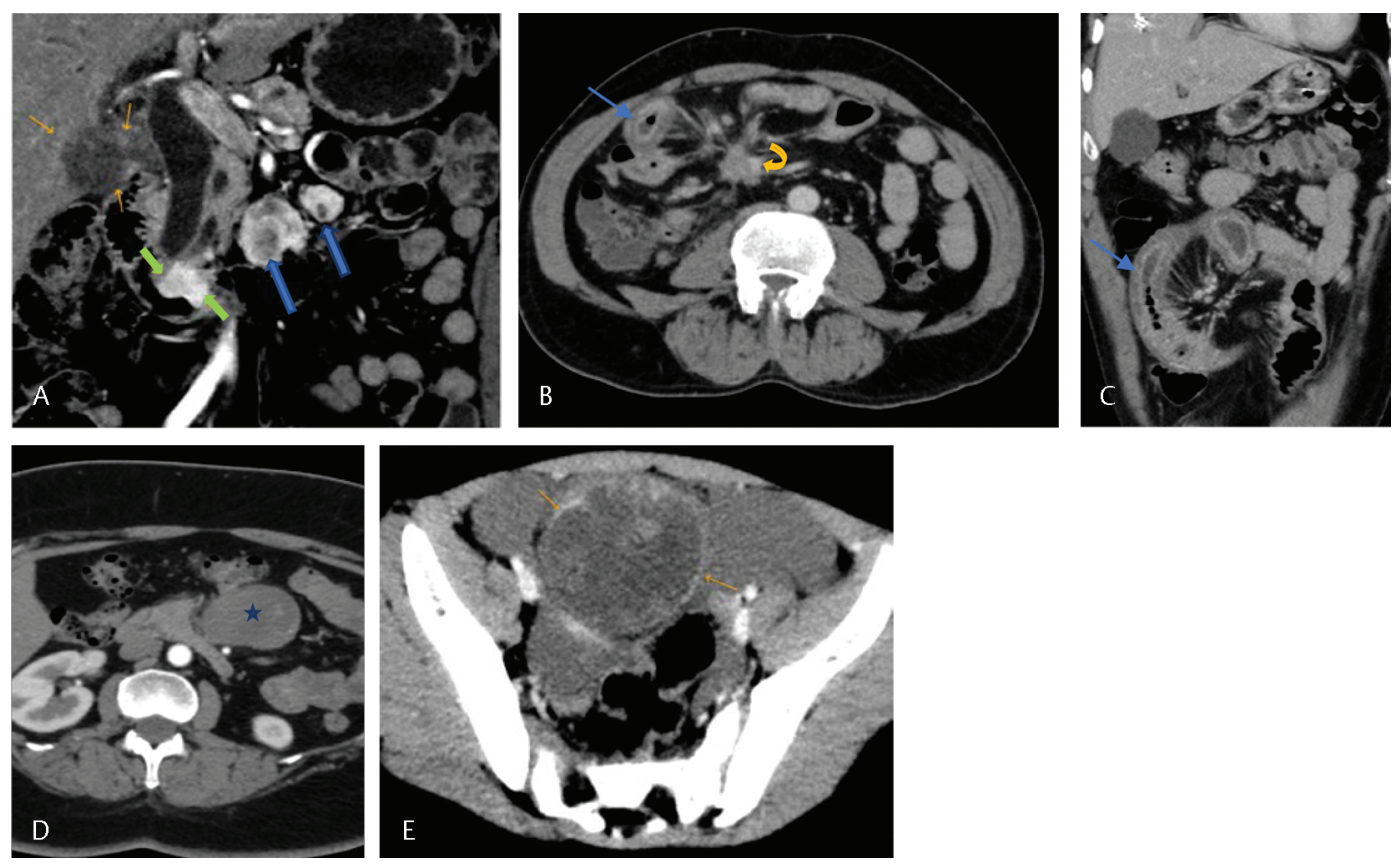

Fig. 9 Coronal arterial phase CT abdomen: avidly enhancing solid mass along the medial wall of the duodenum (red arrows), duodenal carcinoid with similar avidly enhancing nodal metastases at root of mesentery (blue arrows). There is an associated gall bladder adenocarcinoma (yellow arrows). (B, C) Axial portal phase contrast enhanced CT abdomen: Mildly enhancing irregular spiculated lesion in the mesentery (curved yellow arrow), associated with bowel wall edema in adjacent small bowel loops (blue arrows) due to venous ischemia, mesenteric carcinoid. (D) Axial arterial phase contrast enhanced CT: Solid hypodense mass in the mesentery with no hyperenhancement (blue star) - mesenteric desmoid. (E) Axial portal-venous phase contrast enhanced CT of a 7-year-old girl shows a hypodense circumscribed mass with internal heterogeneous as well as peripheral enhancement (arrows), inflammatory myofibroblastic pseudotumor. CT, computed tomography. 
considered to be neoplastic, they are often associated with elevated inflammatory markers. ${ }^{42-44}$

They may be echogenic, iso-, or hypoechoic on US with internal vascularity and demonstrate heterogeneous enhancement patterns ( - Fig. 9E), sometimes with early peripheral enhancement and delayed fill in on CECT owing to fibrous components. They are FDG PET avid and on MRI are iso- or hypointense to muscle depending on the internal fibrous content. ${ }^{40}$

Gastrointestinal stromal tumor can arise from anywhere along the gut, from the esophagus to the anus ( - Fig. 10A-C), forming the most common mesenchymal tumors. They arise from the interstitial cells of Cajal in the muscularis propria, usually during middle age. In the gut, their most common locations are the stomach and small intestine..$^{26,45}$

They appear as circumscribed enhancing soft-tissue masses without mesenteric edema or invasion of adjacent organs or vessels, and are unlikely to present as small bowel obstruction. ${ }^{26}$ Their slow indolent growth means they are often detected when large with intralesional necrosis and hemorrhage seen within. Poor prognostic factors include size $>5 \mathrm{~cm}$, lobulated contour, heterogeneous enhancement, ulceration, mesenteric fat infiltration, regional lymphadenopathy, or an exophytic growth pattern. They are not associated with ascites but do metastasize to the liver and peritoneum. ${ }^{46}$ Diagnosis is straightforward due to their expression of CD117 antigen (also called the c-KIT). Associations are known with neurofibromatosis 1 and the Carney's triad. ${ }^{45}$

A differential diagnosis of leiomyosarcoma (-Fig. 10 D, E) may be entertained when presented with a large solid heterogeneously enhancing mass in the seventh decade. The latter tumors will be negative for c-KIT and CD34. ${ }^{46}$

Neurogenic tumors: primary neurogenic tumors of the mesentery are very rare. Neurogenic tumors are more common in the retroperitoneum are usually seen in the abdomen among children and young adults (42-60\% of cases). Retroperitoneal ganglioneuromas (benign) and ganglioneuroblastomas (intermediate) are lobulated soft tissue masses, involving the root of the small bowel mesentery by extension, where they are seen to encase the vessels without vascular compromise (-Fig. 11). ${ }^{47}$ Mesenteric schwannomas have been reported but are extremely rare. ${ }^{48}$

\section{Nodal Masses of the Mesentery}

These are the most common solid masses of the mesentery and have a varied differential. Mesenteric nodes $<5 \mathrm{~mm}$
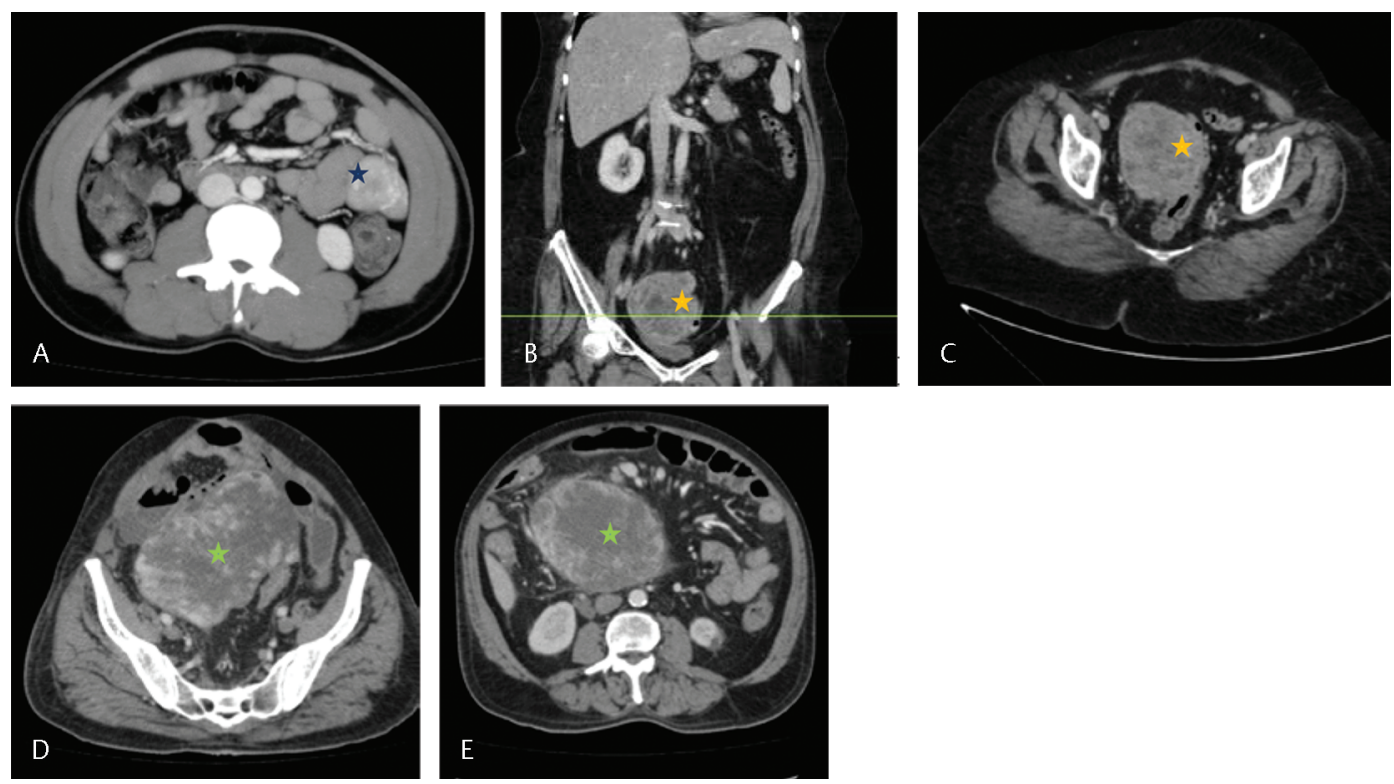

Fig.10 (A) Axial portal phase CT abdomen: solid enhancing mass measuring $<5 \mathrm{~cm}$ arising in close proximity to the jejunum (blue star), jejunal gastrointestinal stromal tumor (GIST). (B, C) Coronal and axial contrast enhanced portal phase CT: Solid heterogeneously enhancing mass in close proximity to the sigmoid (yellow stars)- sigmoid GIST. (D, E) Large lobulated heterogeneously enhancing mass in small bowel mesentery with no necrosis in a 68-year old man (green stars), leiomyosarcoma in the mesentery. CT, computed tomography.
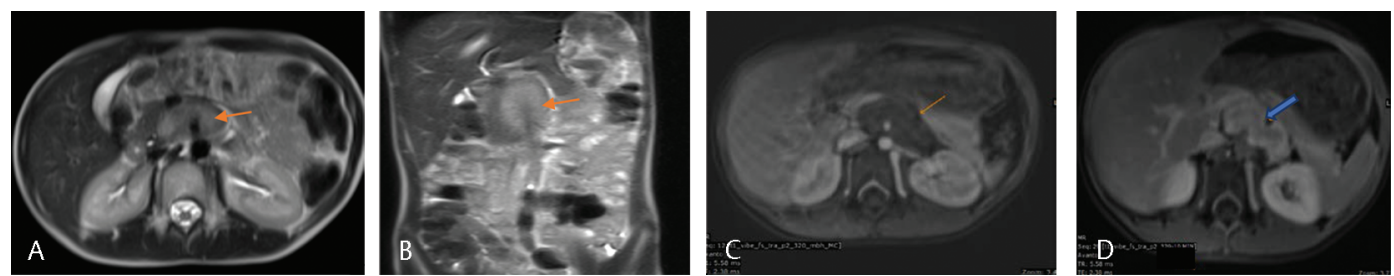

Fig. 11 A 9-year-old child with biopsy proven ganglioneuroma. (A, B) Axial and coronal T2 HASTE MRI demonstrates a mildly T2 hyperintense prevertebral (predominantly retroperitoneal) mass with secondary extension into root of mesentery (arrows) (C, D) T1 fat suppressed postcontrast MRI demonstrates poor enhancement of mass in portal phase (arrow) with characteristic delayed enhancement (thick blue arrow). 
$(4.6 \mathrm{~mm})$ in short axis diameter ${ }^{49}$ are routinely seen in asymptomatic patients on multidetector CT. Size and morphological characterization of abnormal nodes facilitates differentiation of a etiology ( - Table 4)..$^{50,51}$

Metastases to mesenteric nodes commonly arise from pancreas and gastrointestinal tract: colon and small bowel, adenocarcinoma, and carcinoid. However, they can also be involved in breast malignancy and small cell cancer of lung, as well as melanoma, bladder tumor, leukemia, and Kaposi's sarcoma. ${ }^{49}$

Metastatic nodes are of soft tissue attenuation with diffuse homogeneous enhancement, sometimes showing central necrosis ( - Fig. 12A, B). ${ }^{49,51}$

Lymphoma is a common cause of malignant mesenteric lymphadenopathy, usually seen at clustered at the root, sometimes distributed in the distal mesentery or as a combined pattern. ${ }^{40}$ The mesentery is most commonly involved by Non-Hodgkin's lymphoma (45\%) as opposed to
3 to $5 \%$ in Hodgkin's disease..$^{52-54}$ The nodes may be discrete or grow to coalesce and form bulky uniformly enhancing nodal masses encasing the mesenteric vessels forming the "sandwich sign" (- Fig. 12C-E). ${ }^{55}$ Post radiochemotherapy, the nodes may demonstrate cavitation or calcification. FDG PET scans are used staging and end of treatment response depending on the type of lymphoma. ${ }^{56}$

Mesenteric adenitis presents in adults and children with abdominal pain, often with a clinical diagnosis of suspected appendicitis (Table 5). The presence of round ileocolic nodes of 5 to $10 \mathrm{~mm}$ in the right iliac fossa with a normal appendix ( - Fig. 13A, B) and a terminal ileal thickness of $<5 \mathrm{~mm}$ is then called primary mesenteric adenitis. ${ }^{57,58}$

Enlarged mesenteric nodes in the presence of appendicitis, inflammatory bowel disease, diverticulitis, or systemic lupus erythematosus are termed secondary mesenteric adenitis. ${ }^{49}$

These nodes are enlarged enhancing and usually oval. Yersinia enterocolitica infection involves right lower quadrant

Table 4 Nodal masses of the mesentery

\begin{tabular}{|l|l|l|}
\hline Malignant & Infectious & Inflammatory \\
\hline - Lymphoma & - Tuberculosis & - Castleman's \\
- Nodal & - Appendicitis & disease \\
- Carcinoid & - Enteritis & - Whipple's \\
- Kaposi's & - Mesenteric & disease \\
sarcoma & - Diverticulitis & - Crohn's disease \\
& & - Sclerosing \\
& & - Spesenteritis \\
& & - Sarcoidosis \\
\hline
\end{tabular}

Table 5 Mesenteric adenitis

\begin{tabular}{|l|}
\hline Secondary \\
\hline Mesenteric adenitis $>5 \mathrm{~mm}$ \\
\hline Secondary \\
\hline Appendicitis \\
\hline Ulcerative colitis \\
\hline Diverticulitis \\
\hline Crohn's disease \\
\hline Systemic lupus erythematosus \\
\hline Primary \\
\hline Right lower quadrant nodes with ileal thickness of $<5 \mathrm{~mm}$ \\
\hline
\end{tabular}
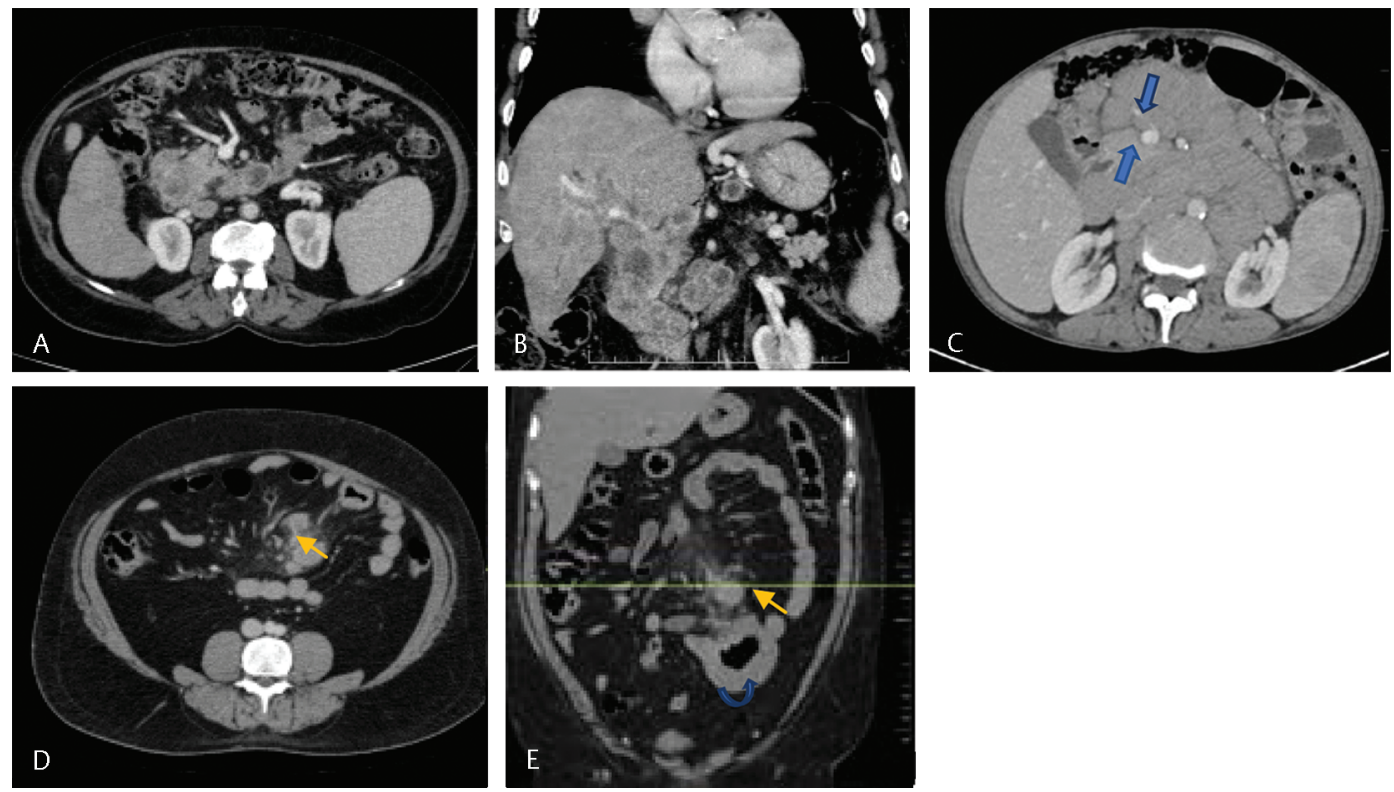

Fig. 12 (A, B) Axial and coronal reformat of contrast enhanced CT in a patient with abdominal discomfort and loss of weight demonstrates necrotic metastatic nodal mass in the mesentery from a heterogeneously enhancing periampullary carcinoma. (C) Bulky conglomerate mass of lymph nodes in the root of the mesentery, on either side of the mesenteric vessels (blue arrows) forming the mesenteric 'sandwich sign'. (D, E) Axial and coronal contrast enhanced CT abdomen in a patient with rigors and left upper quadrant pain demonstrates circumferential wall thickening andaneurysmal dilatation of a loop of small bowel (curved blue arrow) with an associated enlarged mesenteric lymph nodes (yellow arrows), small bowel lymphoma. CT, computed tomography. 

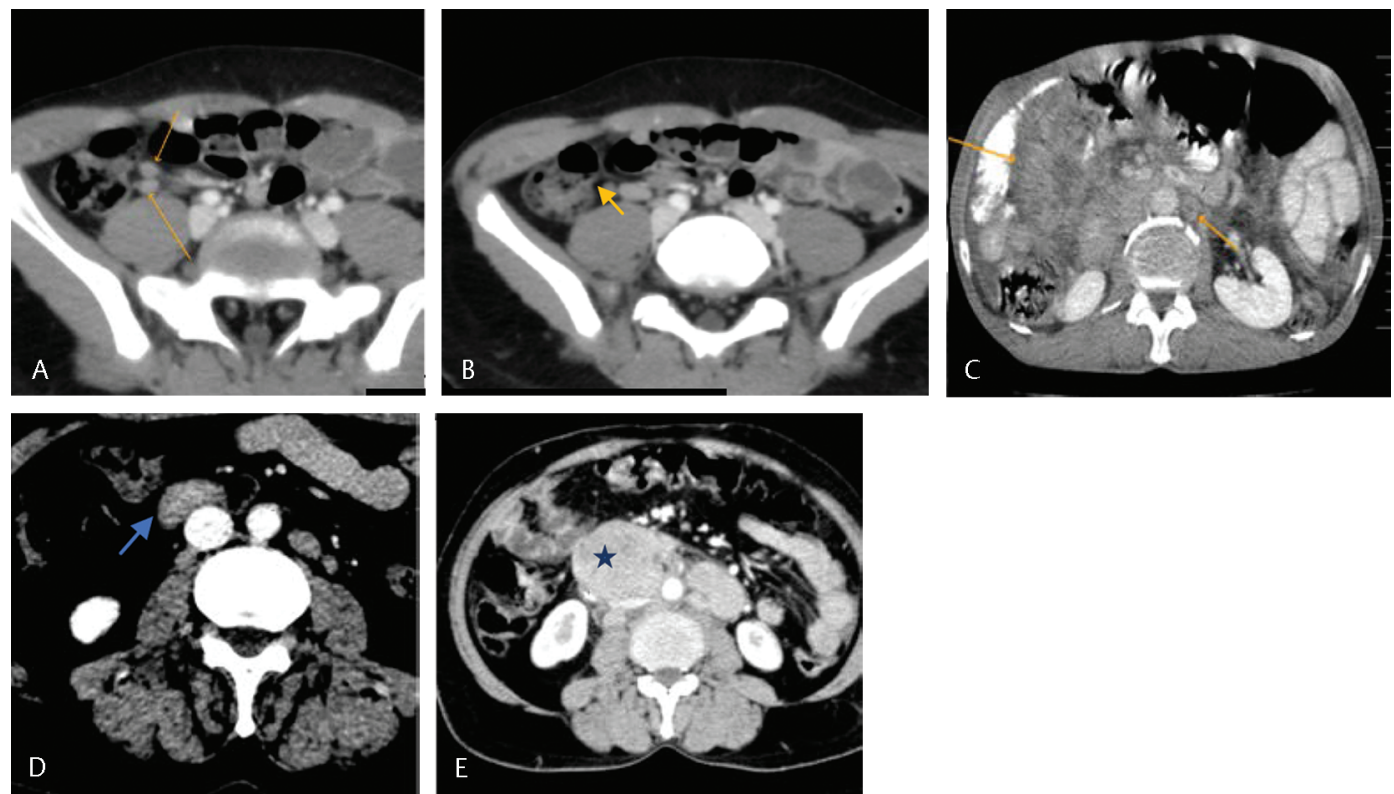

Fig. 13 (A, B) Axial contrast enhanced CT of a 7-year-old child on evaluation for appendicitis demonstrates round ileocolic nodes (arrows) with a normal appendix (not shown), primary mesenteric adenitis. (C) Cystic nodes (arrows) in a patient with proven tuberculosis. (D) “Black pearl” sign (blue arrow) seen in a retroperitoneal node in a patient with sarcoidosis. (E) 46-year-old lady evaluated with contrast enhanced CT for lymphadenopathy detected on general health screen. Biopsy-proven Castleman's disease plasma cell type (blue star). CT, computed tomography.

nodal enlargement with associated thickening of the terminal ileum resembling Crohn's disease. ${ }^{49,59}$

Granulomatous diseases causing mesenteric adenopathy include tuberculosis and sarcoidosis. Tuberculous mesenteric adenopathy (-Fig. 13C) may be isolated or associated with gastrointestinal, omental, and peritoneal disease with or without ascites. The nodes are cystic, discrete, or clustered in character but usually do not attain the massive sizes seen in lymphoma. They often show rim enhancement due to central cavitation or caseation. Sarcoidosis does not affect the mesentery alone and is usually associated with retroperitoneal nodes ( - Fig. 13D). The black pearl sign of sarcoid nodes has been described as a characteristic finding. ${ }^{60}$

Unusual causes include Castleman's disease and Whipple's disease. Whipple's disease is seen in young white males, is caused by a bacterium called Tropheryma whipplei, and is seen as enlarged mesenteric nodes of very low attenuation (10-20 $\mathrm{HU}$ ) on $\mathrm{CT}$, due to internal fat content. Intestinal manifestations include mucosal nodularity in the jejunal loops, thickened mucosal folds, and prominent small bowel loops. ${ }^{61}$

Hypoattenuating and cavitating bulky upper mesenteric lymph nodes demonstrating internal fat content or cystic components are also noted in some patients with gluten-related enteropathy (celiac disease). ${ }^{62,63}$ Other imaging features of celiac disease are fluid filled prominence of small bowel loops with dilution of oral contrast, flocculation of barium, telescoping, intussusception, and conformation (bowel loops apposed to each other with their walls conforming to one another without an intervening space) of small bowel loops. ${ }^{63}$

Castleman's disease is a nonneoplastic lymphoproliferative disease presenting with significantly enlarged hyperenhancing abdominal or mesenteric nodes ( - Fig. 13E),

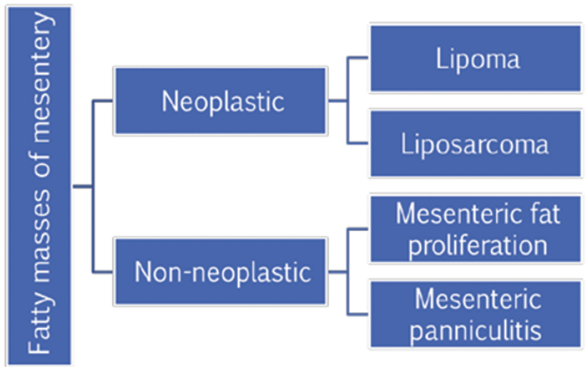

Fig. 14 Fatty masses of mesentery.

commonly unicentric, and solitary nodal, sometimes multinodal. 54,64 Some patients develop systemic symptoms and lymphoma is a top differential. ${ }^{53}$

\section{Fatty Lesions of the Mesentery}

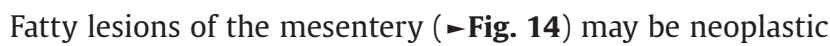
and nonneoplastic. Among the nonneoplastic fatty masses, mesenteric panniculitis, and sclerosing mesenteritis have already been discussed. Fat appears hyperechoic on US and on CT it has an attenuation of 10 to $100 \mathrm{HU}$.

MRI is exemplary in detection of microscopic fat, well depicted on in-phase and out-phase sequences. Macroscopic fat appears hyperintense on $\mathrm{T} 1$ and hypointense on T1 fat-suppressed series ${ }^{65}$ However, most fatty tumors of the mesentery are easily characterized on CT, MRI being used only for problem solving, when the fraction of fat within a lesion is very small.

Mesenteric lipoma is a rare benign tumor, sometimes presenting in children, appearing as soft echogenic lesion on US, giving in to probe compression with no vascularity and displacing 
bowel loops around it. They resemble well-differentiated fatty tumors on CT and are usually excised if large or symptomatic. ${ }^{65}$

Liposarcomas include well differentiated, myxoid, pleomorphic, and round cell types are very unusual in the mesentery but is discussed here in view of a case that presented in our practice. ${ }^{65-67}$ They are commonly seen in the retroperitoneum and displace the small bowel and mesentery by mass effect. The myxoid type often resembles a cystic lesion on plain CT ( Fig. 15A, B), while diffuse enhancement with contrast demonstrates the solid nature of the lesion on CT and MRI. ${ }^{65-67}$ Thick enhancing septations and solid components are seen in well-differentiated liposarcomas, often with internal calcification. The pleomorphic and round cell varieties are largely solid enhancing tumors on CT, difficult to differentiate from other sarcomas. ${ }^{67}$

Mesenteric fat proliferation is a manifestation of chronic inflammation of small bowel. Classically, described as proliferation of fat in the mesentery of abnormal inflamed small bowel usually along the mesenteric side, it can extend circumferentially. ${ }^{17}$ It is an important marker of Crohn's disease, appropriately called "creeping fat" ( Fig. 15C, D).$^{68}$ Considerable perirectal fat proliferation can also be seen in ulcerative colitis, ${ }^{69,70}$ bearing testimony to the chronicity of the disease, but is not a specific indicator for ulcerative colitis, since it can also be seen in Crohn's involving large bowel (-Fig. 15E, F).

Mesenteric lymphangiomas have already been described and are thin-walled fluid or fat attenuation lesions. ${ }^{62}$ They may be multiloculated and typically demonstrate transcompartmental extension, insinuating into areas of least resistance.

\section{Nonmass Miscellaneous Mesenteric Diseases}

Nonneoplastic diseases of the mesentery are very often overlooked because they are soft markers of disease. However, they often provide important clues to underlying systemic events.

\section{Mesenteric Edema}

Non inflammatory mesenteric edema has been described as misty mesentery. It could be a result increased water logging due systemic causes such as chronic kidney disease, hypoproteinemia, cardiac ( Fig. 16A, B), and hepatic failure..$^{25,31}$ Misty mesentery can be differentiated from mesenteric panniculitis by the presence of associated ascites and by absence of fat rim sign and mesenteric nodes.

Localized causes may be vascular as in portal or SMV thrombosis ( - Fig. 16C) or vasculitis, as well as contusion, trauma, or surgery. Enteric infections, hepatic and other malignancies, contraceptive pills, and hypercoagulopathies can result in portal and SMV thrombosis. Pancreatitis and cirrhosis may also predispose to thrombosis leading to mesenteric edema. ${ }^{71}$

\section{Mesenteric Trauma}

It is difficult to distinguish mesenteric blood from edema, but increased densities of 40 to $90 \mathrm{HU}$ are noted in hematoma and clinical history is crucial to make the diagnosis. The "sentinel clot" sign representing a focus of high density may indicate the source of hemorrhage. ${ }^{25}$ Contrast extravasation from mesenteric vessels may be elicited on delayed imaging $\left(-\right.$ Fig. 16D, E) ${ }^{72}$
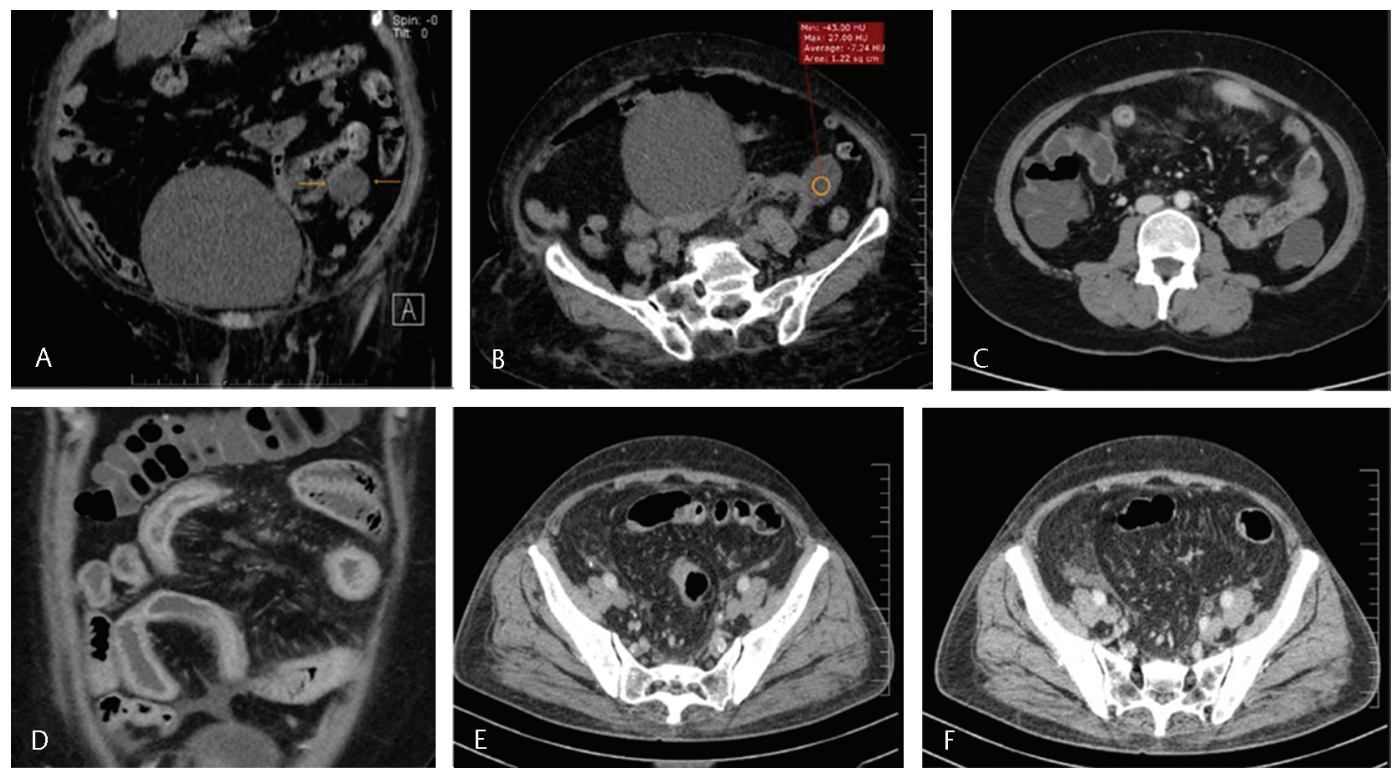

Fig. 15 (A, B) Elderly lady being evaluated for abdominal pain, incidentally detected left paraenteric well circumscribed cystic appearing lesion (arrows) with internal fat content, liposarcoma. (C, D) Mesenteric fat proliferation displacing inflamed small bowel loops along the mesenteric border is very specific as in this case of Crohn's disease. (E, F) Pericolonic fat proliferation is nonspecific and may be seen in Crohn's or ulcerative colitis. 

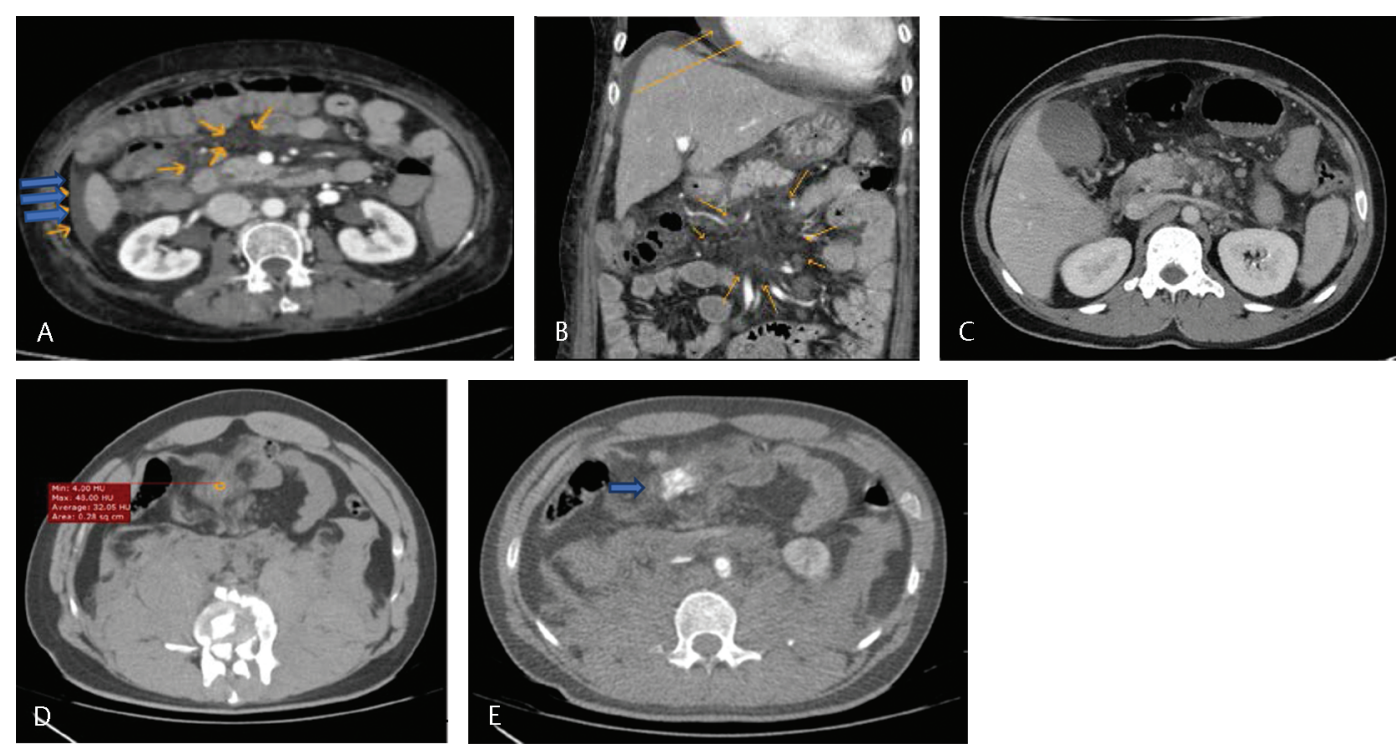

Fig. 16 (A, B) Misty mesentery (short arrows), edema in the presence of cardiac failure. Note the pericardial effusion (long arrows) and ascites (blue arrows). (C) Portal vein thrombosis with mesenteric edema in a 66-year-old man with cirrhosis and hepatocellular carcinoma (not shown). (D, E) Mesenteric trauma and tear with contrast extravasation (blue arrow). There is a traumatic vertebral burst fracture associated with retroperitoneal hematoma seen on - Fig. 16D.

In trauma, a high index of suspicion needs to be maintained, because if there is localized mesenteric edema or fluid sans bowel wall abnormalities, there is often an associated mesenteric tear or laceration of a mesenteric vessel. ${ }^{73}$

\section{Mesenteric Inflammation}

Pancreatitis is the most widespread cause of mesenteric inflammation all over the world. Inflammatory fat stranding, fluid pockets, and fat necrosis extend and evolve with the severity and chronicity of inflammation. Splenic and SMA pseudoaneurysm are a complication of pancreatitis.

Inflammatory bowel disease is another important cause of mesenteric inflammation and encompasses haziness and stranding in the mesenteric fat and congested vasa recta (in the acute setting), also known as the "comb" sign. Fibrofatty proliferation and fat wrapping of the bowel is seen as a chronic manifestation. Mesenteric thickening may also be seen in chronic cases and may cause technical difficulties at surgery. ${ }^{11,74}$

Other common causes include diverticulitis, appendicitis and cholecystitis. Inflamed jejunal and sigmoid diverticula may extend into their anchoring mesentery, with formation of abscesses if they progress. ${ }^{11,25}$

\section{Mesenteric Nonrotation}

Traditionally, as a result of embryological intestinal rotation, the small bowel mesentery is attached to the posterior abdominal wall via a wide mesenteric root which extends from the duodenojejunal flexure on the left of the vertebral column to the right iliac fossa ${ }^{75}$ with the large bowel subtended around the periphery. Malrotation or nonrotation results in the small bowel on the right (-Fig. 17A, B) and the large bowel on the left with a short small bowel mesentery, which forms a pivot around which the small bowel can volve. ${ }^{75}$ There are many variations of abnormal rotation, as a result of which clinical presentation may be in infancy or adulthood.

\section{Internal Mesenteric Hernia}

An internal mesenteric hernia occurs across a congenital or acquired defect in the mesentery, usually in the vicinity of the ligament of Treitz or the terminal ileum. These may be of a transmesenteric subtype, involving both the peritoneal layers, or an intramesenteric type, involving a single layer of peritoneum. ${ }^{76}$ They are the most common internal hernia in children, with pediatric cases accounting for 35\%. ${ }^{77}$ Acquired causes may be related to prior trauma, surgery, inflammation, or ischemia. They tend to have a rather acute presentation of bowel obstruction. ${ }^{78}$

On imaging, there is small bowel obstruction with dilatation of small bowel loops described to be abutting the abdominal wall without intervening omental fat and abnormal location of the bowel loops lateral or posterolateral to the colon. Associated findings of stretched mesenteric vessels converging at the hernial orifice and rightward displacement of mesenteric vessels may be noted. ${ }^{76}$

The "SMV beaking" sign indicating attenuation and beak-like configuration of the SMV, as well as reversal of the SMA-SMV relationship, in the distal aspect ("crisscross appearance") have been described in relation to postoperative mesenteric hernias after the laparoscopic Roux-en-Y gastric bypass. ${ }^{77}$

These hernias may be challenging to detect on imaging because these loops are not covered by a sac and may be present anywhere in the peritoneal cavity. ${ }^{76}$ Complications such as volvulus, ischemia, and strangulation may ensue due to the small size of the mesenteric aperture $(2-3 \mathrm{~cm}) \cdot{ }^{78}$ 

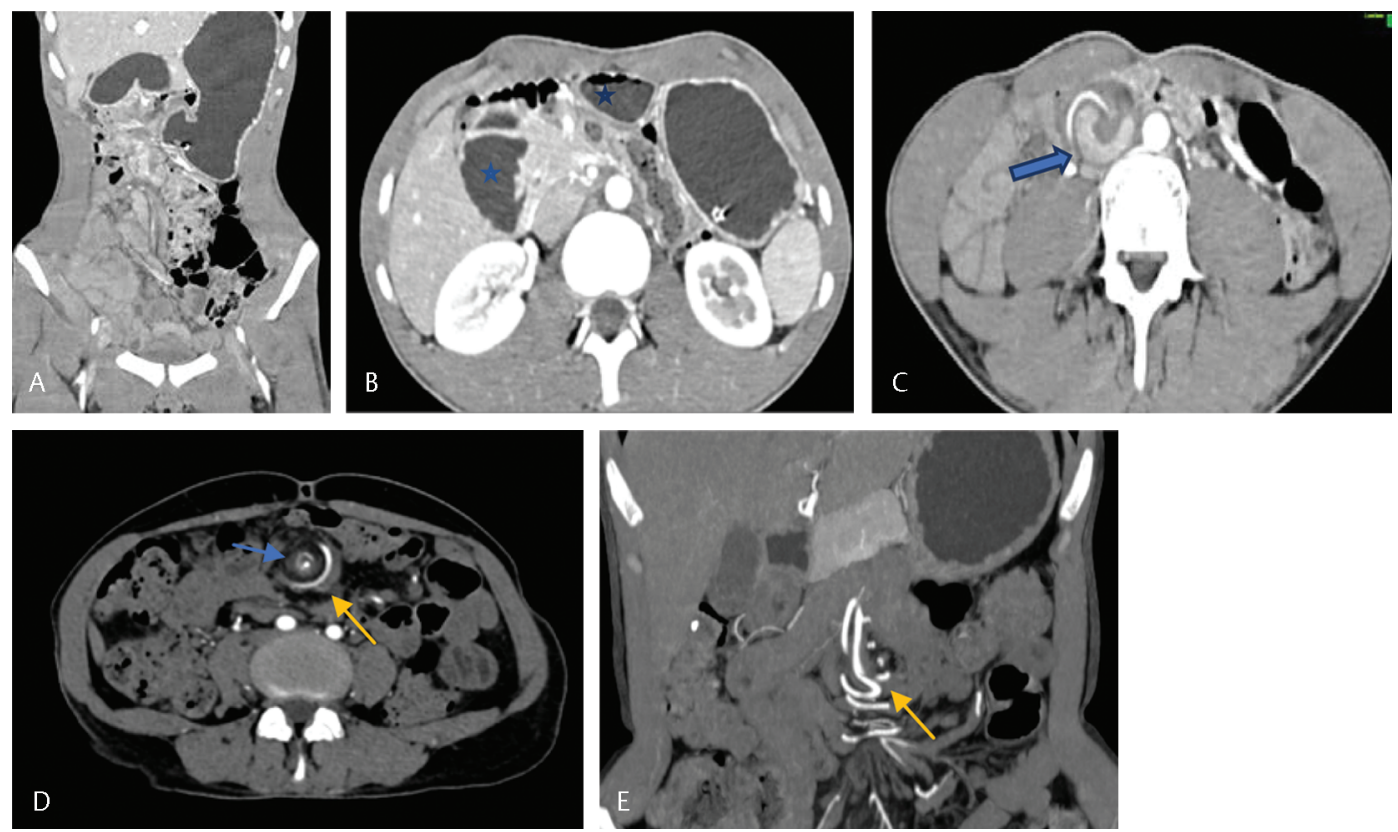

Fig. 17 Malrotation with midgut volvulus. A young adult presenting with pain abdomen and vomiting. (A). Contrast enhanced CT abdomen (coronal reformat) demonstrates small bowel on the right side of the abdomen and large bowel on the left side. (B) Dilated stomach, as well as first and second parts of duodenum (blue stars), and (C) volvulus of the small bowel mesentery with a "whirl sign" (blue arrow). (D, E) Case of idiopathic chronic midgut volvulus without malrotation in a 40 -year-old lady presenting with long-standing intermittent pain abdomen. CT with contrast (axials and coronal reformats) demonstrating swirling of mesenteric vessels (yellow arrows) and central edematous mesentery showing calcification within (blue arrow). CT, computed tomography.
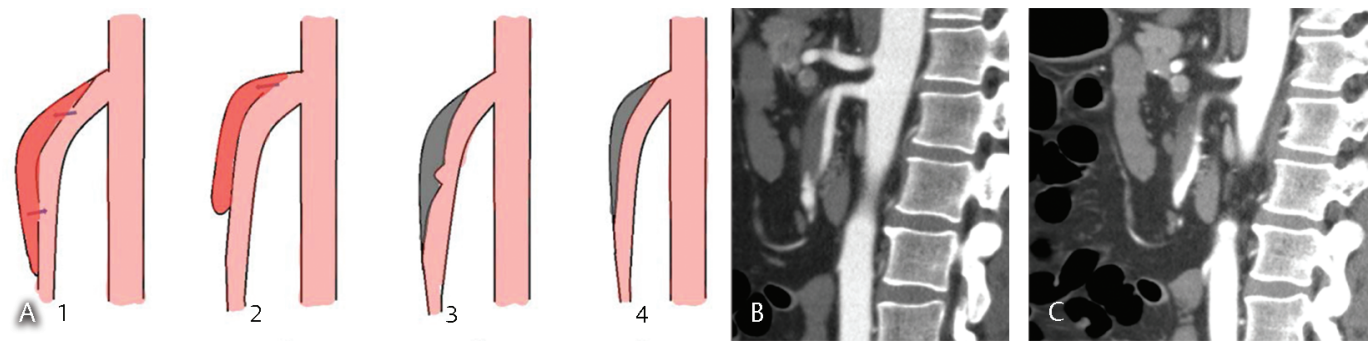

Fig. 18 (A)Graphic representation of SMA dissection. (1) Type I, patent false lumen with both entry and reentry; (2) type II, "cul-de-sac" shaped false lumen without re-entry; (3) type III, thrombosed false lumen with ulcer; (4) type IV, completely thrombosed false lumen without ulcer. (B, C) 48-year-old male was admitted as an emergency with upper abdominal pain since 3 days that worsened overnight, past surgical history includes subtotal colectomy, ileostomy, and cholecystectomy. Sagittal reconstructed CT demonstrates SMA dissection with thrombosis. CT, computed tomography.

\section{Mesenteric Volvulus}

Mesenteric volvulus is a twisting of the mesentery around itself ( - Fig. 17C) which may be a result of congenital nonrotation, congenital bands, idiopathic, or due to adhesions. Often in closed loop obstruction, there is a cone-shaped engorged mesentery with small bowel at the periphery and fluid in the mesentery due to mesenteric ischemia. If unaddressed, this leads to bowel wall ischemia, nonenhancing, paper thin bowel wall, progressing to necrosis, and gas in the mesenteric veins. ${ }^{79}$

\section{Superior Mesenteric Artery Disease}

Thrombosis of the SMA is a relatively common cause of small bowel ischemia in patients with extensive atherosclerotic disease. Embolism and dissection extending into the SMA are rarer causes of acute mesenteric ischemia that should not be overlooked. It may be seen as an intravascular filling defect on contrast CT or hyperattenuating thrombus on plain $\mathrm{CT}$, in addition to the findings of segmental bowel wall edema and bowel dilatation due to adynamic ileus with or without mesenteric edema in acute arterial occlusions. ${ }^{80}$ Dissection in the SMA is rare cause of small bowel ischemia. The extent of luminal compromise influences clinical presentation and management and is therefore classified (-Fig. 18A, B). Among vasculitic diseases, Takayasu's vasculitis is seen in younger individuals and usually results in formation of collateral arcades which are well depicted at CECT. However, they are also predisposed to thrombosis and mesenteric ischemia. ${ }^{80}$ Rapid and accurate diagnosis is crucial for implementation of medical or surgical management.

\section{New Concepts and Trends}

The traditional anatomical description of the mesentery has been questioned and reevaluated in recent years. The 
mesentery has been given the exalted position of an organ. The discovery is credited to J Calvin Coffey, at the University Hospital Limerick. According to Coffey et al, ${ }^{1,4,10}$ the mesentery is contiguous from the stomach to the anal canal expunging the theory that some segments of the small and large bowel are retroperitoneal. In his article, he validates the finding of anatomist Toldt and Rosa, way back in $1879.9^{4,10} \mathrm{He}$ also presents a new understanding of diseases involving the mesentery, categorizing them into primary, and secondary mesenteropathies.

\section{Conclusion}

The mesentery is indeed an extraordinary structure, with an intriguing relationship with the bowel. Within the abdomen, it is a flexible, pliant shield of the adipose tissue acting as a tether, yet allowing for mobility of the bowel. The diseases of the mesentery as described above are intrinsic to the nature of the mesenteric structure. An understanding of the mesenteric structure is imperative to assess the radiological features of infective, inflammatory, vascular, and neoplastic processes within. As in any other organ, correlation with presentation and clinical findings are essential to the formation of a sound primary and differential diagnosis. In addition, there is new and exciting research on the mesentery with promise to unravel more mysteries of the mesentery.

\section{Conflict of Interest}

None declared.

\section{Acknowledgments}

The authors would like to acknowledge Dr. Renu Jadiya for her contribution to case collection and diagrams.

\section{References}

1 Zheng MH, Zhang S, Feng B. Complete mesocolic excision: Lessons from anatomy translating to better oncologic outcome. World J Gastrointest Oncol 2016;8(3):235-239

2 Boylan M. The digestive and “circulatory" systems in Aristotle's biology. J Hist Biol 1982;15(1):89-118

3 Coffey JC, O'Leary DP. The mesentery: structure, function, and role in disease. Lancet Gastroenterol Hepatol 2016; 1(3):238-247

4 Toldt C, Rosa AD. Bau und Wachstumsveranterungen der Gekrose des menschlischen Darmkanales. Denkschrdmathnaturwissensch 1879;41:1-56

5 Byrnes KG, Walsh D, Lewton-Brain P, McDermott K, Coffey JC. Anatomy of the mesentery: historical development and recent advances. Semin Cell Dev Biol 2019;92:4-11

6 Gray H, Anatomy of the Human Body; Philadelphia, PA: Lea and Febiger; 1918: 1157

7 Treves F. Lectures on the anatomy of the intestinal canal and peritoneum in man. BMJ 1885;1(1264):580-583

8 Dodds WJ, Darweesh RM, Lawson TL, et al. The retroperitoneal spaces revisited. AJR Am J Roentgenol 1986;147(6):1155-1161

9 Nicholas G, Panos P, Maria D, Imaging of peritoneum, mesentery and omentum. In: Adam A, Dixon AK, Gillard JH, Cornelia M, eds. Grainger \& Allison's Diagnostic Radiology: A Textbook of Medical Imaging 6th edition. New York, NY: Churchill Livingstone; 2015: 704-721
10 Meyers MA. Intraperitoneal spread of malignancies and its effect on the bowel. Clin Radiol 1981;32(2):129-146

11 Coffey JC, Kiernan M, Shaheel SM, Pathology of the mesentery. In: Coffey JC, Lavery I, Sehgal R, eds. Mesenteric Principles of Gastrointestinal Surgery. 1st ed. Boca Raton, FL: CRC Press, Taylor \& Francis Group; 2017: 85-108

12 Levine MS, Rubesin SE, Laufer I. Pattern approach for diseases of mesenteric small bowel on barium studies. Radiology 2008;249(2):445-460

13 Coffey JC, Dockery P, Moran BJ, et al. Mesenteric and peritoneal anatomy. In: Coffey JC, Lavery I, Sehgal R, eds. Mesenteric Principles of Gastrointestinal Surgery. 1st ed. Boca Raton, FL: CRC Press, Taylor \& Francis Group; 2017: 11-40

14 Levy AD, Shaw JC, Sobin LH. Secondary tumors and tumorlike lesions of the peritoneal cavity: imaging features with pathologic correlation. Radiographics 2009;29(2):347-373

15 Rizvi SA, Syed W, Shergill R. Approach to pseudomyxoma peritonei. World J Gastrointest Surg 2018;10(5):49-56

16 Dong P, Chen JJ, Wang XZ, Wang YQ. Intraperitoneal tuberculous abscess: Computed tomography features. World J Radiol 2015;7(9):286-293

17 Sakurai T, Katsuno T, Saito K, et al. Mesenteric findings of CT enterography are well correlated with the endoscopic severity of Crohn's disease. Eur J Radiol 2017;89:242-248

18 Ghai S, Metser U, Mesentery, omentum, peritoneum: cystic masses and neoplasms. In: Hamm B, Ros PR, eds. Abdominal Imaging. Berlin-Heidelberg, Germany: Springer; 2013: 1589-1600

19 Stoupis C, Ros PR, Abbitt PL, Burton SS, Gauger J. Bubbles in the belly: imaging of cystic mesenteric or omental masses. Radiographics 1994;14(4):729-737

20 Trinh TW, Kennedy AM. Fetal ovarian cysts: review of imaging spectrum, differential diagnosis, management, and outcome. Radiographics 2015;35(2):621-635

21 Karhan AN, Soyer T, Gunes A, et al. Giant omental cyst (lymphangioma) mimicking ascites and tuberculosis. Iran J Radiol 2016;13(3):e31943

22 Arraiza M, Metser U, Vajpeyi R, et al. Primary cystic peritoneal masses and mimickers: spectrum of diseases with pathologic correlation. Abdom Imaging 2015;40(4):875-906

23 Pedrosa I, Saíz A, Arrazola J, Ferreirós J, Pedrosa CS. Hydatid disease: radiologic and pathologic features and complications. Radiographics 2000;20(3):795-817

24 Ilica AT, Kocaoglu M, Zeybek N, et al. Extrahepatic abdominal hydatid disease caused by Echinococcus granulosus: imaging findings. AJR Am J Roentgenol 2007;189(2):337-343

25 Taffel MT, Khati NJ, Hai N, Yaghmai V, Nikolaidis P. De-misty-fying the mesentery: an algorithmic approach to neoplastic and non-neoplastic mesenteric abnormalities. Abdom Imaging 2014;39(4):892-907

26 Winant AJ, Vora A, Ginter PS, Levine MS, Brylka DA. More than just metastases: a practical approach to solid mesenteric masses. Abdom Imaging 2014;39(3):605-621

27 Akram S, Pardi DS, Schaffner JA, Smyrk TC. Sclerosing mesenteritis: clinical features, treatment, and outcome in ninety-two patients. Clin Gastroenterol Hepatol 2007;5(5):589-596, quiz 523-524

28 Emory TS, Monihan JM, Carr NJ, Sobin LH. Sclerosing mesenteritis, mesenteric panniculitis and mesenteric lipodystrophy: a single entity? Am J Surg Pathol 1997;21(4):392-398

29 Singh AK, Gervais DA, Hahn PF, Sagar P, Mueller PR, Novelline RA. Acute epiploic appendagitis and its mimics. Radiographics 2005;25(6):1521-1534

30 Corwin MT, Smith AJ, Karam AR, Sheiman RG. Incidentally detected misty mesentery on CT: risk of malignancy correlates with mesenteric lymph node size. J Comput Assist Tomogr 2012;36(1):26-29 
31 McLaughlin PD, Filippone A, Maher MM. The "misty mesentery": mesenteric panniculitis and its mimics. AJR Am J Roentgenol 2013;200(2):W116-23

32 Zissin R, Metser U, Hain D, Even-Sapir E. Mesenteric panniculitis in oncologic patients: PET-CT findings. $\mathrm{Br} \mathrm{J}$ Radiol 2006;79(937):37-43

33 Levy AD, Sobin LH. From the archives of the AFIP: Gastrointestinal carcinoids: imaging features with clinicopathologic comparison. Radiographics 2007;27(1):237-257

34 Elsayes KM, Menias CO, Bowerson M, Osman OM, Alkharouby AM, Hillen TJ. Imaging of carcinoid tumors: spectrum of findings with pathologic and clinical correlation. J Comput Assist Tomogr 2011;35(1):72-80

35 Pantongrag-Brown L, Buetow PC, Carr NJ, Lichtenstein JE, Buck JL. Calcification and fibrosis in mesenteric carcinoid tumor: CT findings and pathologic correlation. AJR Am J Roentgenol 1995;164(2):387-391

36 Buck JL, Sobin LH. Carcinoids of the gastrointestinal tract. Radiographics 1990;10(6):1081-1095

37 Modlin IM, Lye KD, Kidd M. A 5-decade analysis of 13,715 carcinoid tumors. Cancer 2003;97(4):934-959

38 Strosberg J. Neuroendocrine tumours of the small intestine. Best Pract Res Clin Gastroenterol 2012;26(6):755-773

39 Sakorafas GH, Nissotakis C, Peros G. Abdominal desmoid tumors. Surg Oncol 2007;16(2):131-142

40 Chung EM, Biko DM, Arzamendi AM, Meldrum JT, Stocker JT. Solid tumors of the peritoneum, omentum, and mesentery in children: radiologic-pathologic correlation: from the radiologic pathology archives. Radiographics 2015;35(2):521-546

41 Levy AD, Rimola J, Mehrotra AK, Sobin LH. From the archives of the AFIP: benign fibrous tumors and tumorlike lesions of the mesentery: radiologic-pathologic correlation. Radiographics 2006;26(1):245-264

42 Aptel S, Gervaise A, Fairise A, et al. Abdominal inflammatory myofibroblastic tumour. Diagn Interv Imaging 2012;93(5):410-412

43 Coffin CM, Hornick JL, Fletcher CDM. Inflammatory myofibroblastic tumor: comparison of clinicopathologic, histologic, and immunohistochemical features including ALK expression in atypical and aggressive cases. Am J Surg Pathol 2007;31(4):509-520

44 Lai LM, McCarville MB, Kirby P, et al. Shedding light on inflammatory pseudotumor in children: spotlight on inflammatory myofibroblastic tumor. Pediatr Radiol 2015;45(12):1738-1752

45 Miettinen M, Lasota J. Gastrointestinal stromal tumors-definition, clinical, histological, immunohistochemical, and molecular genetic features and differential diagnosis. Virchows Arch 2001;438(1):1-12

46 Scola D, Bahoura L, Copelan A, Shirkhoda A, Sokhandon F. Getting the GIST: a pictorial review of the various patterns of presentation of gastrointestinal stromal tumors on imaging. Abdom Radiol (NY) 2017;42(5):1350-1364

47 Rha SE, Byun JY, Jung SE, Chun HJ, Lee HG, Lee JM. Neurogenic tumors in the abdomen: tumor types and imaging characteristics. Radiographics 2003;23(1):29-43

48 Tepox Padrón A, Ramírez Márquez MR, Cordóva Ramón JC, Cosme-Labarthe J, Carrillo Pérez DL. Mesenteric schwannoma: an unusual cause of abdominal mass. Rev Esp Enferm Dig 2017;109(1):76-78

49 Lucey BC, Stuhlfaut JW, Soto JA. Mesenteric lymph nodes seen at imaging: causes and significance. Radiographics 2005;25(2):351-365

50 Padhani AR, Imaging in the evaluation of cancer. In: Nicholson T, ed. Recommendations for Cross-Sectional Imaging in Cancer Management, 2nd ed. London, United Kingdom: The Royal College of Radiologists; 2014

51 Abdel Gawad EA, Abu Samra MF, Talat AM. The utility of multidetector $\mathrm{CT}$ in detection and characterization of mesenteric lymphadenopathy with histopathological confirmation. Egypt J Radiol Nucl Med 2016;47(3):757-764

52 Frampas E. Lymphomas: Basic points that radiologists should know. Diagn Interv Imaging 2013;94(2):131-144

53 Yenarkarn P, Thoeni RF, Hanks D. Case 107: lymphoma of the mesentery. Radiology 2007;242(2):628-631

54 Manzella A, Borba-Filho P, D’Ippolito G, Farias M. Abdominal manifestations of lymphoma: spectrum of imaging features. ISRN Radiol 2013;2013:483069

55 Hardy SM. The sandwich sign. Radiology 2003;226(3):651-652

56 Johnson SA, Kumar A, Matasar MJ, Schöder H, Rademaker J. Imaging for staging and response assessment in lymphoma. Radiology 2015;276(2):323-338

57 Macari M, Hines J, Balthazar E, Megibow A. Mesenteric adenitis: CT diagnosis of primary versus secondary causes, incidence, and clinical significance in pediatric and adult patients. AJR Am J Roentgenol 2002;178(4):853-858

58 Radin R. Acute mesenteric and retroperitoneal lymphadenitis in systemic lupus erythematosus: case report. Abdom Imaging 2001;26(4):411-413

59 Maconi G, Di Sabatino A, Ardizzone S, et al. Prevalence and clinical significance of sonographic detection of enlarged regional lymph nodes in Crohn's disease. Scand J Gastroenterol 2005;40(11):1328-1333

60 Venkata Ramanan R, Pudhiavan A, Venkataramanan A. The "cluster of black pearls" sign of sarcoid lymphadenopathy: a new sign on thin-section contrast-enhanced multidetector CT. Clin Radiol 2017;72(9):729-736

61 Ratnaike RN. Whipple's disease. Postgrad Med J 2000;76(902):760-766

62 Fultz PJ, Hampton WR, Skucas J, Sickel JZ. Differential diagnosis of fat-containing lesions with abdominal and pelvic CT. Radiographics 1993;13(6):1265-1280

63 Scholz FJ, Afnan J, Behr SC. CT findings in adult celiac disease. Radiographics 2011;31(4):977-992

64 Bonekamp D, Horton KM, Hruban RH, Fishman EK. Castleman disease: the great mimic. Radiographics 2011;31(6): 1793-1807

65 Pereira JM, Sirlin CB, Pinto PS, Casola G. CT and MR imaging of extrahepatic fatty masses of the abdomen and pelvis: techniques, diagnosis, differential diagnosis, and pitfalls. Radiographics 2005;25(1):69-85

66 Dani RD, Gandhi V, Thakkar GN, Parmar KI, Nanavati K. Mesenteric lipoma: a rare benign tumor in the pediatric abdomen. Indian J Radiol Imaging 2003;13:41-42

67 Shin NY, Kim MJ, Chung JJ, Chung YE, Choi JY, Park YN. The differential imaging features of fat-containing tumors in the peritoneal cavity and retroperitoneum: the radiologic-pathologic correlation. Korean J Radiol 2010;11(3):333-345

68 Golder WA. The "creeping fat sign"-really diagnostic for Crohn's disease? Int J Colorectal Dis 2009;24(1):1-4

69 Bruining DH, Zimmermann EM, Loftus EV Jr, Sandborn WJ, Sauer CG, Strong SA; Society of Abdominal Radiology Crohn's Disease-Focused Panel. Consensus recommendations for evaluation, interpretation, and utilization of computed tomography and magnetic resonance enterography in patients with small bowel Crohn's disease. Radiology 2018;286(3): 776-799

70 Thoeni RF, Cello JP. CT imaging of colitis. Radiology 2006;240(3):623-638

71 Ponziani FR, Zocco MA, Campanale C, et al. Portal vein thrombosis: insight into physiopathology, diagnosis, and treatment. World J Gastroenterol 2010;16(2):143-155

72 Yu J, Fulcher AS, Turner MA, Cockrell C, Halvorsen RA. Blunt bowel and mesenteric injury: MDCT diagnosis. Abdom Imaging 2011;36(1):50-61

73 Brody JM, Leighton DB, Murphy BL, et al. CT of blunt trauma bowel and mesenteric injury: typical findings and pitfalls in 
diagnosis. Radiographics 2000;20(6):1525-1536, discussion 1536-1537

74 Panizza PS, Viana PC, Horvat N, et al. Inflammatory bowel disease: current role of imaging in diagnosis and detection of complications: gastrointestinal imaging. Radiographics 2017;37(2):701-702

75 Okino Y, Kiyosue H, Mori H, et al. Root of the small-bowel mesentery: correlative anatomy and CT features of pathologic conditions. Radiographics 2001;21(6):1475-1490

76 Sandhu PS, Joe BN, Coakley FV, Qayyum A, Webb EM, Yeh BM. Bowel transition points: multiplicity and posterior location at CT are associated with small-bowel volvulus. Radiology 2007;245(1):160-167
77 Lanzetta MM, Masserelli A, Addeo G, et al. Internal hernias: a difficult diagnostic challenge. Review of CT signs and clinical findings. Acta Biomed 2019;90(5-S, suppl 5) :20-37

78 Doishita S, Takeshita T, Uchima Y, et al. Internal hernias in the era of multidetector CT: correlation of imaging and surgical findings. Radiographics 2016;36(1):88-106

79 Dilauro M, McInnes MD, Schieda N, et al. Internal hernia after laparoscopic Roux-en-Y gastric bypass: optimal CT signs for diagnosis and clinical decision making. Radiology 2017;282(3):752-760

80 ZhaoYE,WangZJ,ZhouCS,ZhuFP,ZhangLJ,LuGM.Multidetector computed tomography of superior mesenteric artery: anatomy and pathologies. Can Assoc Radiol J 2014;65(3): 267-274 